\title{
Analysis, design and implementation of sensorless $V / f$ control in a surface-mounted PMSM without damper winding
}

\author{
SOURABH PAITANDI* and MAINAK SENGUPTA \\ Department of Electrical Engineering, Indian Institute of Engineering Science and Technology, \\ Shibpur, Howrah 711103, India \\ e-mail: sourabh350@gmail.com; sourabh.rs2013@ee.iiests.ac.in; msg@ee.iiests.ac.in
}

MS received 14 March 2016; revised 26 July 2016; accepted 28 September 2016

\begin{abstract}
This paper presents a novel, reliable and efficient $V / f$ control implementation on a 8-pole, $750 \mathrm{rpm}$, $5 \mathrm{~kW}$ surface-mounted permanent magnet synchronous motor (PMSM) without damper winding. In the absence of a damper winding, open loop $V / f$ control of SM is inherently unstable, particularly at high speeds. Stabilisation can be done with proper stator frequency modulation in accordance with the change in rotor speed to provide for effect of damping. This has been implemented here without use of any shaft-mounted encoder. The change in rotor speed is observed from power perturbation, thereby eliminating the need for using a speed sensor in the drive. The efficiency of the drive is further increased with appropriate control of the power factor, irrespective of load and frequency variations. Simulated and experimental results are presented for both openloop and the proposed $V / f$ control. These results establish the accuracy of the design of the proposed $V / f$ control strategy and the precision of hardware implementation. A comparative study between the proposed $V / f$ control method and standard vector control method, as implemented on this PMSM, has also been presented here to establish the advantages of the proposed scheme. The PMSM itself was designed and fabricated in the laboratory.
\end{abstract}

Keywords. Surface-mounted PMSM; V/f control; sensorless control; stabilisation of PMSM; efficiency optimisation.

\section{Introduction}

Use of permanent magnet synchronous motor (PMSM)based drives is increasing in several applications due its well-known advantages. Different control techniques such as vector control, direct torque control and $V / f$ control with or without position/speed sensor are being used in the PMSM drive [1-3]. Although, both the vector control and direct torque control techniques yield fast dynamics, the $V / f$ control is one of the simplest control techniques, where the speed of the PMSM can be controlled by varying the supply frequency. Use of $V / f$ control first started for induction motor (IM) which does not require very fast dynamic response. Various techniques were reported for improvement of $V / f$-control-based IM drive performance [4, 5]. However, the open-loop $V / f$ control of wound-field synchronous motor without damper winding is inherently unstable beyond a certain frequency range [6,7], which has been discussed later in this paper. The stabilisation can be done by providing for the effect of damping torque using an appropriate control strategy during speed transients of the rotor [7]. The methods of stabilising a reluctance

*For correspondence synchronous motor using a speed sensor is reported in [8]. An additional speed sensor or position sensor, as used in most cases, increases the cost and reduces the system reliability. The use of $V / f$ control for PMSM was first reported in [9]. Different stabilisation techniques with proper power factor control technique using DC-link current sensing [9], DC-link peak current control [10], rotor position estimation using stator voltage and current have also been reported in literature. $V / f$ control can be used for the line start PMSM with damper winding in rotor [11]. However, due to different design complexities and to have cost reduction, most of the PMSMs do not have damper winding [11]. Perera et al [12] suggested a stabilisation technique using input power perturbation along with a voltage control method for constant flux linkage operation and power factor control, but implemented in a IPMSM with damper windings, which has vastly different electromechanical dynamics (in comparison with surface-mounted PMSM (spmsm) without damper winding) since in IPMSM $L_{q}>L_{d}$. Additionally, in IPMSMs the buried PMs are mechanically secured against torque and unbalanced magnetic pull transient. For stable V/f operation of these PMSMs, the damping torque is provided by controlling the torque angle $(\delta)$ during speed transients. The present paper 
presents the design and implementation of a novel sensorless stabilisation technique with power factor control for surface-mounted PMSMs. The efficiency of the drive has been increased by controlling the terminal power factor $(\simeq$ internal power factor, since $\delta$ is small) of the PMSM by controlling the reactive power. The power factor control strategy suggested and implemented in this paper is much simpler than suggested in $[10,12]$. The proposed $V / f$ control scheme is shown in figure 1.

This paper also presents a comparative study between the proposed $V / f$ control and the conventional vector-controlbased drive both implemented on this fabricated PMSM. The vector control scheme has been implemented here with a shaft-mounted position encoder. A detailed comparison highlighting the merits and demerits of the proposed drive has also been presented for ready reference.

The entire PMSM drive has been designed, implemented and tested on a laboratory prototype surface-mounted PMSM. The ratings and other important parameters of the system are given in the "Appendix". Interestingly, even the PMSM itself has been designed and fabricated by the authors with the help of a small machine manufacturer using imported magnets $[13,14]$. The PMSM is coupled mechanically to (i) a brakepulley arrangement $(1 \mathrm{~kW})$ and (ii) a $4 \mathrm{~kW}, 110 \mathrm{~V}, 750 \mathrm{rpm}$ DC separately excited generator for loading. This combination of mechanical and electrical loading has been made keeping quite a few interesting issues in mind. At starting and at low speeds the generator develops no emf and hence cannot be used for experiments where the goal is to apply significant load (torque) at low speeds. This is relevant in variable speed in low speeds zone of variable speed drive tests. A mechanical load of full capacity $(5 \mathrm{~kW})$ on the other hand will lead to excessive heating of the brake-pulley mechanism and sustained loading cannot be applied. Additionally, available DC generators of this above rating could be procured with much difficulty. A $5 \mathrm{~kW}$ DC generator at $110 \mathrm{~V}$ (laboratory DC supply is $110 \mathrm{~V}$ )

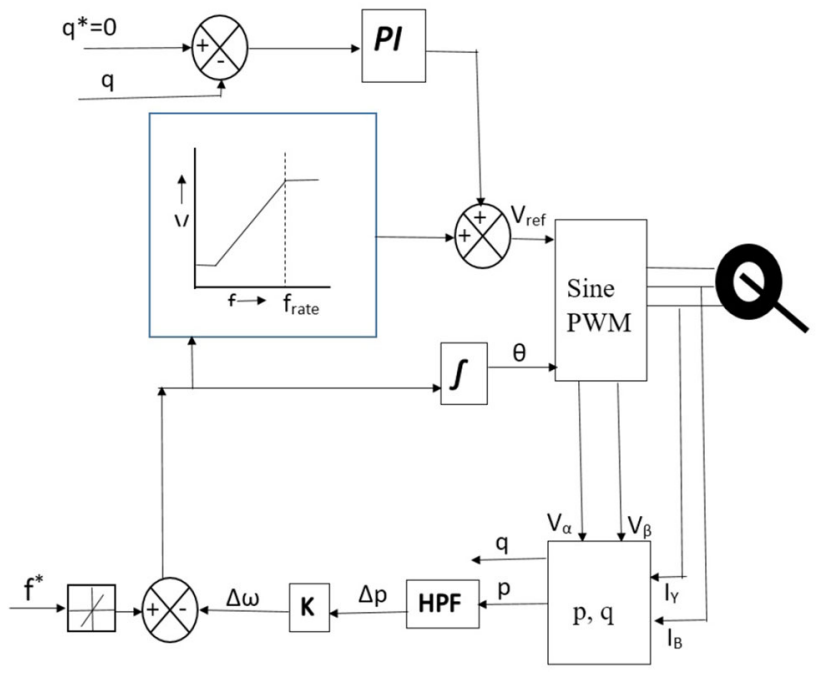

Figure 1. Block diagram of the proposed $V / f$ controller with stabilisation and power factor control. could rarely be located with any vendor; if one such machine is to be specially manufactured on a single-piece basis it would become prohibitively costly as also its size would be much more than the available space in the test bench. Hence, this arrangement was made. The control algorithm has been implemented on an FPGA platform.

\section{Modelling of PMSM}

For the surface-mounted PMSM used here, $L_{d}=L_{q}=\mathrm{L}$ $[13,14]$. The PMSM electromechanical model can be represented by [15]

$$
\begin{gathered}
{\left[\begin{array}{l}
v_{d} \\
v_{q}
\end{array}\right]=\left[\begin{array}{cc}
R+p L & -\omega L \\
\omega L & R+p L
\end{array}\right]\left[\begin{array}{l}
i_{d} \\
i_{q}
\end{array}\right]+\left[\begin{array}{c}
0 \\
\omega \psi_{0}
\end{array}\right]} \\
J \frac{d \omega_{r}}{d t}=\frac{P T_{e}}{2}-B \omega_{r}-\frac{P T_{L}}{2}
\end{gathered}
$$

where $\omega_{r}$ is mechanical speed in elec. $\mathrm{rad} / \mathrm{s}, \omega$ is stator frequency in elec. rad $/ \mathrm{s}, \psi_{0}$ is no-load flux linkage, $P$ is number of poles and $p=\frac{d}{d t}$ is the Heaviside operator. All other symbols have their usual significance. From figure $2, V_{q}=V_{s} \cos \delta$ and $V_{d}=-V_{s} \sin \delta, \delta$ being the load angle. We also know that the electromagnetic torque developed [15] in the motor is

$$
\begin{aligned}
T_{e} & =\frac{P}{2}\left[\left(L_{d}-L_{q}\right) i_{d} i_{q}+\psi_{0} i_{q}\right] \\
& =\frac{P}{2} \psi_{0} i_{q}\left(a s, L_{d}=L_{q}\right) .
\end{aligned}
$$

Hence

$$
J \frac{d \omega_{r}}{d t}=\left(\frac{P}{2}\right)^{2} \psi_{0} i_{q}-B \omega_{r}-\frac{P}{2} T_{L}
$$

For transient analysis of PMSM it is also important to consider the load angle. Figure 3 shows the torque angle $\delta$ during steady and transient states. From figure 3

$$
\Delta \theta=\omega \Delta t-\Delta \delta .
$$

Now, if, $\Delta t \rightarrow 0$, then $\frac{\Delta \theta}{\Delta t}=\omega_{r}$. Hence

$$
\omega_{r}=\omega-\frac{d \delta}{d t}
$$

The state space model of the PMSM can be obtained by rearranging (1)-(4). However, these equations contain nonlinear terms. Therefore it is necessary to linearise the equations about some nominal operating point. The nonlinear model can be linearised by assuming [12] that

$$
x_{i}=X_{i}+\Delta x_{i}
$$

where $x_{i}$ is the variable, $X_{i}$ is the steady state value and $\Delta x_{i}$ is a perturbation. Thus linearising (1)-(4), the state equations of the $V / f$-controlled drive, we get (5) 


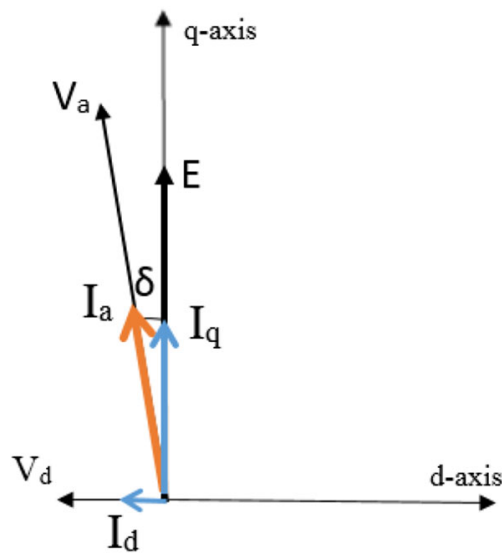

Figure 2. Phasor diagram of PMSM.

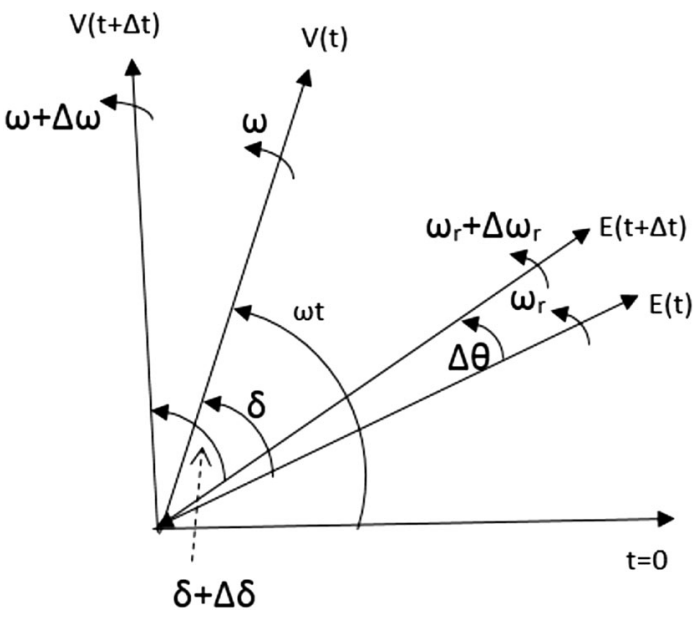

Figure 3. Power angle change of PMSM during transients.

$$
p x=A x+B u
$$

where

$$
\begin{aligned}
& x=\left[\begin{array}{llll}
\Delta i_{d} & \Delta i_{q} & \Delta \omega_{r} & \Delta \delta
\end{array}\right] . \\
& x=\left[\begin{array}{llll}
\Delta i_{d} & \Delta i_{q} & \Delta \omega_{r} & \Delta \delta
\end{array}\right]^{T}, \\
& u=\left[\begin{array}{lll}
\Delta v_{s} & \Delta \omega & \Delta T_{l}
\end{array}\right]^{T}, \\
& A=\left[\begin{array}{cccc}
-R / L & \omega_{r 0} & I_{q} & -\frac{V_{s} \cos \delta_{0}}{L} \\
-\omega_{r 0} & -R / L & \psi_{0} / L & -\frac{V_{s} \sin \delta_{0}}{L} \\
0 & (P / 2)^{2} \frac{\psi_{0}}{J} & -B / J & 0 \\
0 & 0 & -1 & 0
\end{array}\right], \\
& B=\left[\begin{array}{ccc}
-\frac{\sin \delta_{0}}{L} & 0 & 0 \\
\frac{\cos \delta_{0}}{L} & 0 & 0 \\
0 & 0 & -P / 2 J \\
0 & 1 & 0
\end{array}\right]
\end{aligned}
$$

The stability analysis can be verified by the eigenvalues of matrix $|A|$. For steady-state operation at the nominal operating point, $\Delta v_{s}=0$ and $\Delta \omega=0$. For simplicity, it is assumed that motor runs under no load (mechanical losses only), which implies $I_{q} \simeq 0$. Table 1 shows the eigenvalues of matrix $|A|$ at different values of $\omega_{r 0}$ (nominal stator frequency). It can be seen from table 1 that the eigenvalues $\lambda_{3}$ and $\lambda_{4}$ have positive real parts for a stator frequency $=230 \mathrm{rad} / \mathrm{s}(35 \mathrm{~Hz})$ or above, which proves the presence of instability in the open-loop $V / f$ drive. Figure 4 shows machine speed when the speed reference ramps from 0 to $475 \mathrm{rpm}$ (ramping time is $1 \mathrm{~s}$ ) under open-loop $V / f$ control. It can be seen that the machine is stable at this speed. Figure 5 clearly shows that the machine becomes unstable when the speed reference is changed to $550 \mathrm{rpm}$ under open-loop $V / f$ control. The PMSM becomes unstable after the speed reference reaches steady value of $57 \mathrm{rad} / \mathrm{s}(550 \mathrm{rpm})$. The same has also been verified by performing real-time simulation of open-loop $V / f$ control of PMSM (figure 5b) at identical conditions.

\section{Simplified analysis and stabilisation of $V / f$ control drive}

The state space model described earlier is for open-loop systems. However, the electrical time constant is much lesser than the mechanical time constant. Thus we can simplify (5) to (6) as follows;

$$
p\left[\begin{array}{c}
\Delta \omega_{r} \\
\Delta \delta
\end{array}\right]=\left[\begin{array}{cc}
-\frac{J}{B} & 0 \\
1 & 0
\end{array}\right]\left[\begin{array}{c}
\Delta \omega_{r} \\
\Delta \delta
\end{array}\right]+\left[\begin{array}{cc}
0 & \frac{P}{2 J} \\
1 & 0
\end{array}\right]\left[\begin{array}{c}
\Delta \omega \\
\Delta T_{l}
\end{array}\right] .
$$

For a small $\Delta \delta=\delta_{1}, \sin \delta_{1} \longrightarrow \delta_{1}$. Thus, restoring torque $\Delta T_{e}$ is given by

$$
\Delta T_{e}=K_{e} \Delta \delta
$$

The capital letters inserted in the block diagram stand, as per established convention, as the Laplace domain counterpart of the time domain. The block diagram of the system described in (6) is shown in figure 6. For constant-frequency operation, under steady-state condition, $\Delta \omega=0$. Hence, the characteristic equation of the system in figure 6 is given by

Table 1. Eigenvalues of system matrix under open-loop $V / f$ control at different stator frequencies.

\begin{tabular}{cccccc} 
Sl. & $\begin{array}{c}\omega \\
(\mathrm{rad} /\end{array}$ & & & & \\
no. & $\mathrm{s})$ & $\lambda_{1}$ & $\lambda_{2}$ & $\lambda_{3}$ & $\lambda_{4}$ \\
\hline 1 & 105 & $-61+\mathrm{j} 327$ & $-61-\mathrm{j} 327$ & $-48+\mathrm{j} 99$ & $-48-\mathrm{j} 99$ \\
2 & 220 & $-107+\mathrm{j} 324$ & $-107-\mathrm{j} 324$ & $-2.2+\mathrm{j} 233$ & $-2.2-\mathrm{j} 233$ \\
3 & 230 & $-112+\mathrm{j} 328$ & $-112-\mathrm{j} 328$ & $3.4+\mathrm{j} 240$ & $3.4-\mathrm{j} 240$ \\
4 & 314 & $-130+\mathrm{j} 378$ & $-130-\mathrm{j} 378$ & $21+\mathrm{j} 269$ & $21-\mathrm{j} 269$ \\
\hline
\end{tabular}



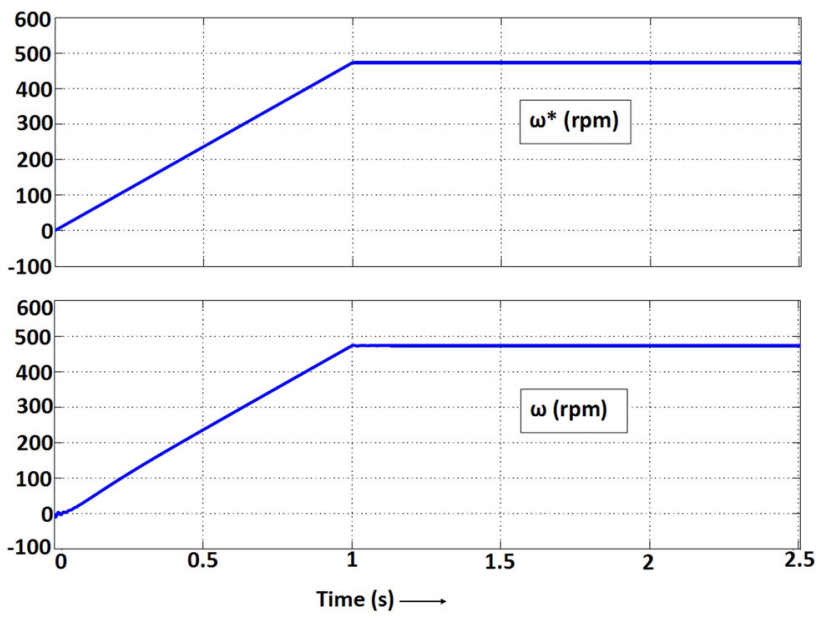

Figure 4. Upper trace: speed reference ramping upto $475 \mathrm{rpm}$, lower trace: speed of machine under open loop $V / f$ control.

$$
s^{2}+\frac{B}{J} s+\frac{P K_{e}}{2 J}=0 .
$$

Now, torque in a PMSM with a damper winding is given by [15]

$$
J \frac{d \omega_{r}}{d t}=\left(\frac{P}{2}\right)^{2} \psi_{0} i_{q}+B \omega+D\left(\omega-\omega_{r}\right)-T_{l}
$$

Equation (9) can be linearised as discussed earlier and the block diagram of figure 7 can be obtained from it. The corresponding characteristic equation with $\Delta \omega=0$ is given by

$$
s^{2}+\left(\frac{B}{J}+\frac{P K_{d}}{2 J}\right) s+\frac{P K_{e}}{2 J}=0 .
$$

Comparing figures 6 and 7a with (8) and (10), it can be observed that in case of PMSM with damper winding, an additional damping term, proportional to the speed difference between the stator and rotor mmf, provides for the necessary damping torque during transients and ensures the stability of the drive. This can be done in $V / f$-controlbased PMSM drive, in the case where damper windings are absent, by modulating the stator frequency in such a way that

$$
\Delta \Omega(s)=-K_{d} s \Delta \Omega_{r}(s) \Rightarrow \Delta \omega=-K_{d} \frac{d \Delta \omega_{r}}{d t}
$$

This modifies the overall system block diagram, which is shown in figure $7 \mathrm{~b}$. The characteristic equation for the modified system is given by

$$
s^{2}+\left(\frac{B}{J}+\frac{P K K_{e}}{2 J}\right) s+\frac{P k_{e}}{2 J}=0
$$

so that the coefficients of the second term in (10) and (12) now resemble each other. Thus after the modulation as in (12), it is evident that modified system has similar characteristics when compared to a PMSM having damper winding and hence it can provide for necessary damping (in an alternative way) with a proper selection of K. However, a speed sensor is required to calculate $\Delta \omega_{r}$. It can be calculated from power perturbation without any speed or position sensor, which is described in the next section. This scheme is another novel contribution of this paper.

\section{Stabilisation using power perturbation}

Electrical energy input of the machine consists of field storage, losses and energy for mechanical work. For small perturbations about the equilibrium point, changes in motor losses are negligible. Also, the stored magnetic energy can be assumed to be constant over a cycle without loss of accuracy. During small rotor perturbations, the perturbation in average power primarily consists of accelerating power

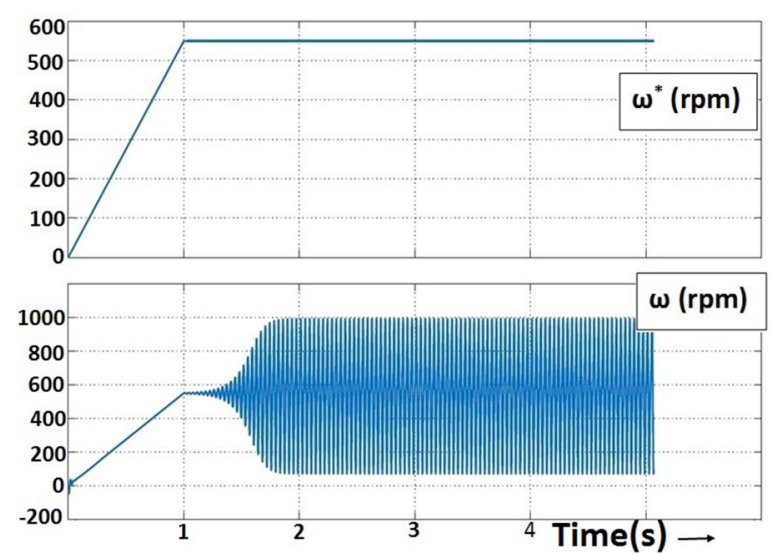

(a)

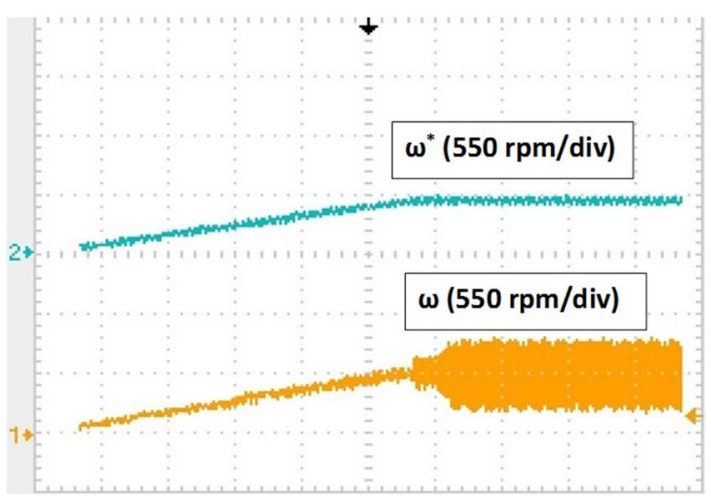

Time $(0.5 s /$ div $) \rightarrow$

(b)

Figure 5. Upper trace: speed reference ramping to $550 \mathrm{rpm}$, lower trace: speed of machine under open loop V/f control; (a) off-line simulation and (b) real-time simulation. 


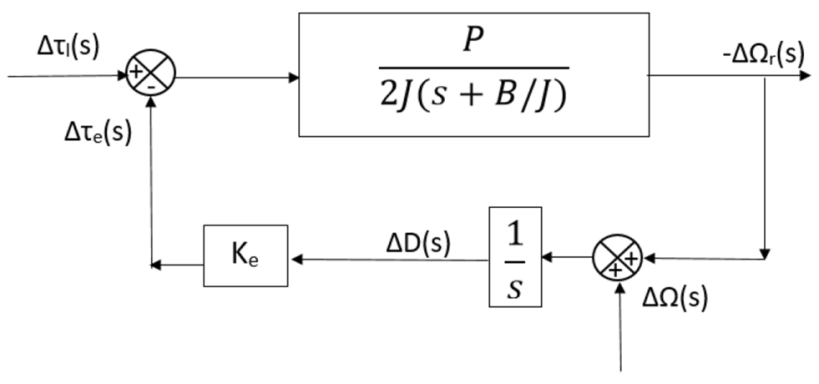

Figure 6. Block diagram of the simplified small signal mechanical model of PMSM without damper winding under $V / f$ control.

and change in load power. The power balance equation can be written as,

$$
\begin{aligned}
p_{e}= & P_{e}+\Delta p_{e} \\
= & \text { Losses }+\frac{d W_{f e}}{d t}+\left(\frac{2}{P}\right)^{2} J \frac{d \omega_{r}^{2}}{d t}+\left(\frac{2}{P}\right)^{2} B \omega_{r}^{2} \\
& +\frac{2}{P} \omega_{r} \Delta T_{l} .
\end{aligned}
$$

Neglecting change in losses and stored magnetic field energy,

$$
\Delta p_{e}=\left(\frac{2}{P}\right)^{2} 2 J \omega_{0} \frac{d \Delta \omega_{r}}{d t}+\frac{2}{P} T_{l 0} \Delta \omega_{r} .
$$

Comparing (11) and (14) it can be observed that $-\Delta p_{e}$, can be used to modulate the frequency reference $(\Delta \omega)$ :

$$
\begin{aligned}
\Delta \omega & =-K \Delta p_{e} \\
& =K\left(\left(\frac{2}{P}\right)^{2} 2 J \omega_{0} \frac{d\left(-\Delta \omega_{r}\right)}{d t}+\frac{2\left(-\Delta \omega_{r}\right)}{P} T_{l 0}\right) .
\end{aligned}
$$

This modifies the system in figure $7 \mathrm{~b}$ into the system of figure 8 . The characteristic equation for the modified system is given by

$$
s^{2}+s\left(\frac{B}{2 J}+\frac{4 K K_{e} \omega_{r}}{P}\right)+\frac{k_{2}}{2 J}\left(P+K K_{e} T_{l 0}\right)=0 .
$$

It is interesting to note that additional damping can be provided through proper selection of $\mathrm{K}$ in Eq. (16).

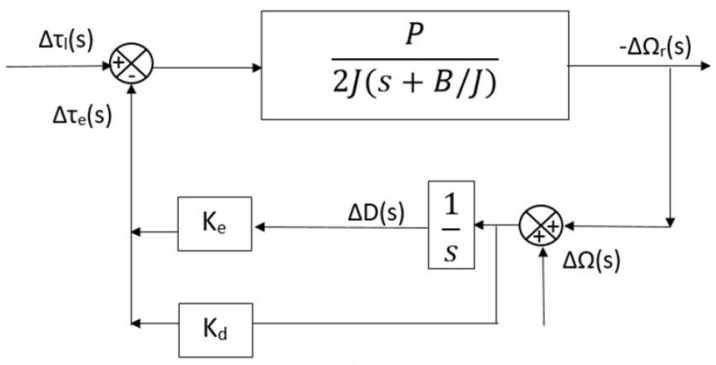

(a)

\subsection{Stability verification of the proposed closed- loop V/f control}

In the proposed control scheme, the stator frequency varies in accordance with active power perturbation. Hence, the stator frequency $\omega$ has to be included as a new state variable in the state space description of the system. The change in active power, $\Delta p_{e}$, can be obtained using a highpass filter (figure 23). Hence

$$
\Delta P_{e}(s)=\frac{s}{s+\frac{1}{\tau}} P_{e}(s)
$$

where $\tau$ is the time constant of high-pass filter. Using (15) and (17)

$$
\Delta \dot{\omega}+\frac{\Delta \omega}{\tau}=-K \dot{p_{e}} .
$$

Now, power input to the machine is

$$
p_{e}=v_{d} i_{d}+v_{q} i_{q} .
$$

Assuming that the supply voltage remains constant [15] (figure 2)

$$
p_{e}=\left(-V_{s} \sin \delta\right) i_{d}+\left(V_{s} \cos \delta\right) i_{q}
$$

Hence

$$
\dot{p_{e}}=V_{s}\left(-\dot{i_{d}} \sin \delta+\dot{i_{q}} \cos \delta-\left(i_{s} \cos \delta+i_{q} \sin \delta\right) \dot{\delta}\right) .
$$

Replacing for $\dot{i_{d}}, \dot{i_{q}}, \dot{\delta}$ (using (5)) in (18) we get

$$
\begin{aligned}
\Delta \dot{\omega} & =K V_{s}\left(\omega_{r} \cos \delta-\frac{R}{L} \sin \delta+\left(\omega-\omega_{r}\right) \cos \delta\right) i_{d} \\
& +K V_{s}\left(\omega_{r} \sin \delta-\frac{R}{L} \cos \delta+\left(\omega-\omega_{r}\right) \sin \delta\right) i_{q} \\
& +K V_{s} \frac{\psi_{0} \cos \delta}{L} \omega_{r}+\frac{K V_{s}}{L}-\frac{\Delta \omega}{\tau} .
\end{aligned}
$$

Equation (22) represents the fifth state equation. Linearisation of this gives the new system for stability analysis. It can be observed from (22) and (12) that the stability of the

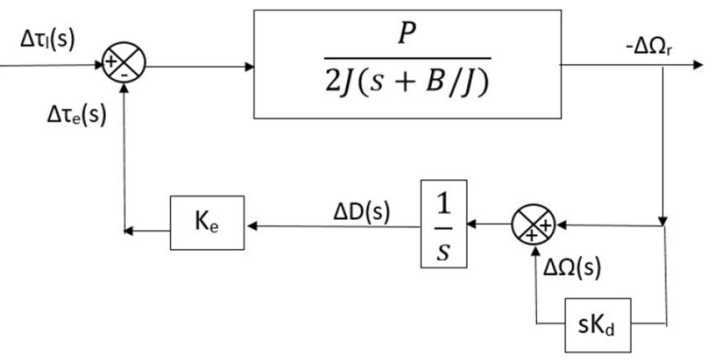

(b)

Figure 7. Block diagram of simplified small-signal model of mechanical dynamics under $V / f$ control: (a) PMSM with damper winding and (b) PMSM without damper winding with controlled frequency modulation. 


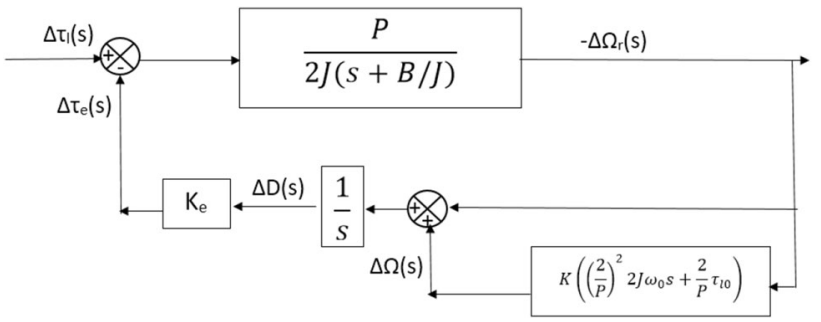

Figure 8. Block diagram of simplified small-signal model of PMSM without damper winding with controlled frequency modulation.

system depends upon value of $K$ and the cut-off frequency $(1 / \tau)$ of the high-pass filter. It has been found from table 2 that for $K=0.02, \lambda_{1}$ and $\lambda_{2}$ (sl. no. 1, table 2) become positive and for $K=0.001, \lambda_{3}$ and $\lambda_{4}$ (sl. no. 4, table 2) become positive. The system is unstable when $0.002>K>0.015$ for any value of $\tau$. Here, $K=0.005$ is chosen. The maximum possible cut-off frequency (here, $16 \mathrm{~Hz}$ ) for proper damping can be obtained from the pole locations (table 3) at rated speed under full-load condition. However here the cut-off frequency of the high-pass filter is chosen as $3.5 \mathrm{~Hz}$ to keep a safe margin. Figure 9 shows the speed response during starting from 0 speed to $750 \mathrm{rpm}$ and during sudden loading of the motor at $750 \mathrm{rpm}$ with the cutoff frequency of $4 \mathrm{~Hz}$ (sl. no. 1, table 3). Very low cut-off frequency makes the settling of speed transients more sluggish.

It can be observed from figure 9 that during sudden loading the actual speed falls for a very short transient period. Simultaneously the frequency reference (i.e. speed reference) reduces, unlike conventional $V / f$ control, where the frequency reference is independent of load and speed variations. This automatic change of supply frequency during speed transients ensures the stability of the system. The change in frequency depends on the amount of loading, gain $K$ and cut-off frequency of HPF. Selection of proper value of $K$ and cut-off frequency ensures proper frequency modulation and hence stability of the drive. Finally the speed comes back to its original value, verifying that there is very good speed regulation.

\subsection{Measurement of power perturbation}

Input power in any 3-phase machine can be calculated as [15] follows:

$$
P=V_{\alpha} I_{\alpha}+V_{\beta} I_{\beta} .
$$

Input power of the PMSM can be calculated using (23) with the help of reference voltages generated for sine PWM and sensed phase current for any chosen DC-link voltage of the inverter. Active power perturbations can be measured using a high-pass filter using the block schematic shown in figure 10.

\section{Power factor control and efficiency optimisation}

For a surface-mounted PMSM, maximum efficiency operation $(\eta)$ is achieved when $I_{d}=0$. Hence, $I_{a}=I_{q}$. It can be understood from figure 11 that the maximum efficiency operation is obtained by minimising the stator copper loss, since other losses are constant. The PMSM used here (actually for all the surface mounted PMSM) has very low inductance $\left(L_{d}=L_{q}=5.5 \mathrm{mH}, \mathrm{X}_{p u}=0.14 \mathrm{pu}\right) \quad$ which results in a low value of full-load torque angle (here fullload torque angle $\delta_{F L}=10^{\circ}$ ).

$$
\begin{aligned}
Z_{\text {base }} & =\frac{V_{\text {base }}(\text { rated phase voltage })}{I_{\text {base }}(\text { rated phase current })}=\frac{145}{12}=12.1 \Omega \\
X_{p u} & =\frac{X_{\text {actual }}}{Z_{\text {base }}}=\frac{314 \times 5.5 \times 10^{-3}}{12.1}=0.14 \mathrm{pu}
\end{aligned}
$$

Table 2. Eigenvalues of system matrix under closed loop $V / f$ control at different values of $K, \omega_{0}=314 \mathrm{rad} / \mathrm{s}$ and $\tau=0.04 \mathrm{under}$ no load.

\begin{tabular}{lcccccc}
\hline Sl. no. & $K$ & $\lambda_{1}$ & $\lambda_{2}$ & $\lambda_{3}$ & $\lambda_{4}$ & $\lambda_{5}$ \\
\hline 1 & 0.02 & $27+\mathrm{j} 415$ & $27+\mathrm{j} 415$ & $-76+\mathrm{j} 199$ & $-76-1 \mathrm{j} 99$ & -130 \\
2 & 0.01 & $-19+\mathrm{j} 377$ & $-19-\mathrm{j} 377$ & $-61+\mathrm{j} 252$ & $-61-\mathrm{j} 252$ & -81 \\
3 & 0.005 & $-78+\mathrm{j} 359$ & $-78-\mathrm{j} 359$ & $-19+\mathrm{j} 276$ & $-19-\mathrm{j} 276$ & -32 \\
4 & 0.001 & $-114+\mathrm{j} 379$ & $-114-\mathrm{j} 379$ & $7.74+\mathrm{j} 261$ & $7.74-\mathrm{j} 261$ & -15 \\
\hline
\end{tabular}

Table 3. Eigenvalues of system matrix under closed-loop $V / f$ control at different values of $\tau, \omega_{0}=314 \mathrm{rad} / \mathrm{s}$ and $K=0.005 \mathrm{under}$ full load.

\begin{tabular}{lccccc}
\hline S1. no. & $\tau(\mathrm{s})[f(\mathrm{~Hz})]$ & $\lambda_{1}$ & $\lambda_{2}$ & $\lambda_{3}$ & $\lambda_{4}$ \\
\hline 1 & $0.04(4)$ & $-69+\mathrm{j} 358$ & $-69-\mathrm{j} 358$ & $-19+\mathrm{j} 232$ & $-19-\mathrm{j} 232$ \\
2 & $0.02(8)$ & $-73+\mathrm{j} 381$ & $-73-\mathrm{j} 381$ & $-14+\mathrm{j} 234$ & $-14-\mathrm{j} 234$ \\
3 & $0.01(16)$ & $-79+\mathrm{j} 391$ & $-79-\mathrm{j} 391$ & $-2.5+\mathrm{j} 235$ & $-2.5-\mathrm{j} 235$ \\
4 & $0.005(32)$ & $-85+\mathrm{j} 396$ & $-85-\mathrm{j} 396$ & $3+\mathrm{j} 239$ & -41 \\
\hline
\end{tabular}




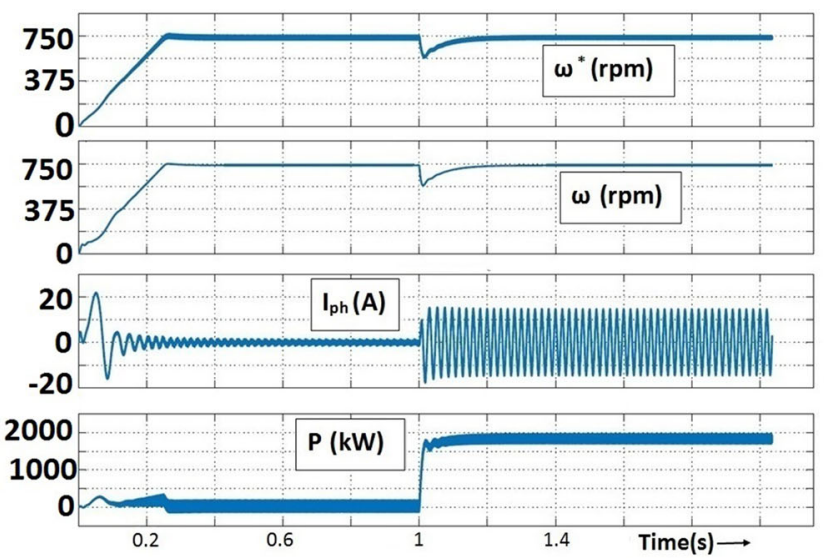

(a)

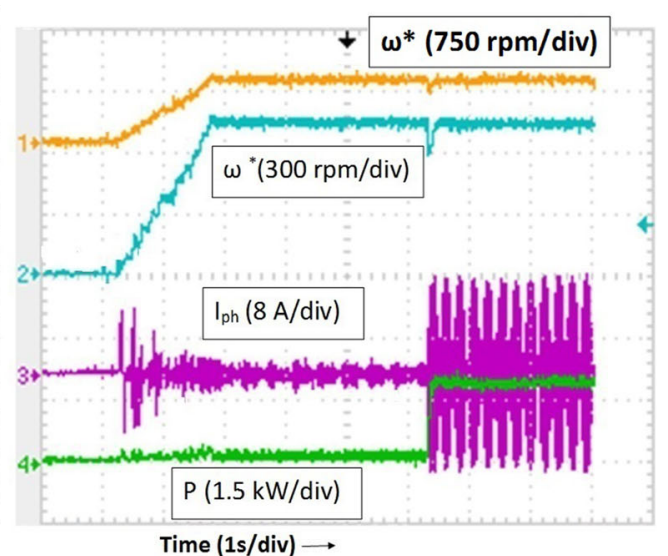

(b)

Figure 9. Speed reference, actual speed, load current and active power traces during sudden loading of $15 \mathrm{Nm}$ with $K=0.005$ and $4 \mathrm{~Hz}$ cut-off frequency: (a) simulated result and (b) experimental result.

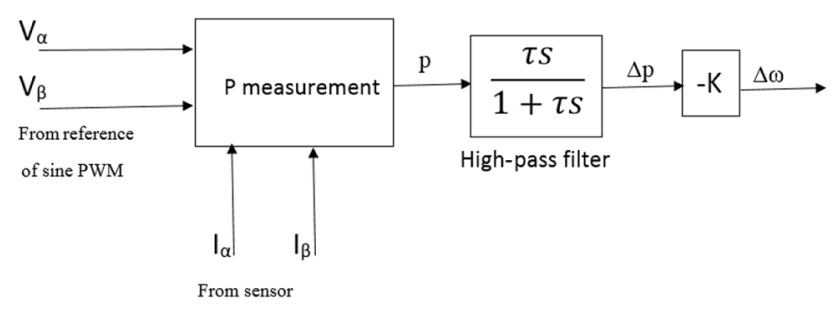

Figure 10. Block diagram showing power perturbation calculation.

This particular feature of the SPMSM leads to the fact that external power factor (when $V_{a}$ and $I_{a}$ are in phase) and internal power factor values (when $E$ and $I_{a}$ are in phasethis corresponds to vector control operation) are extremely close to each other for these machines (figure 2). Unity external power factor gives internal power factor of 0.985 $\left(\cos 10^{\circ}\right)$ at full load.

In the proposed $V / f$ control drive, the back-emf estimation is not performed, so that the scheme remains simple. However, the terminal voltage (voltages used for SPWM) and current (sensed) are known. However

$$
Q=V_{\beta} I_{\alpha}-V_{\alpha} I_{\beta}
$$

It is necessary to make $Q=0$ to maintain external u.p.f. during the entire operation of the drive. It is also well known that reactive power (and hence power factor) of any PMSM can be controlled by controlling the terminal voltage. Here the terminal voltage is maintained at a desired value, which corresponds to u.p.f. This is achieved by measuring $Q$ and maintaining $Q=0$ by a PI controller. A schematic is given in figure 12 . Figure 13 shows the reactive power transients during sudden loading of the machine.

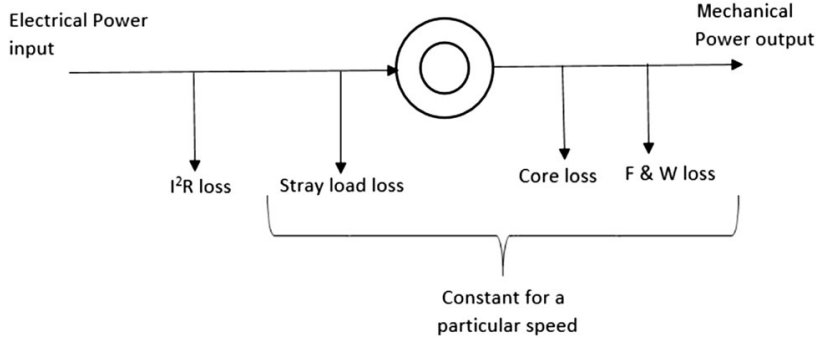

Figure 11. Energy flow diagram in PMSM.

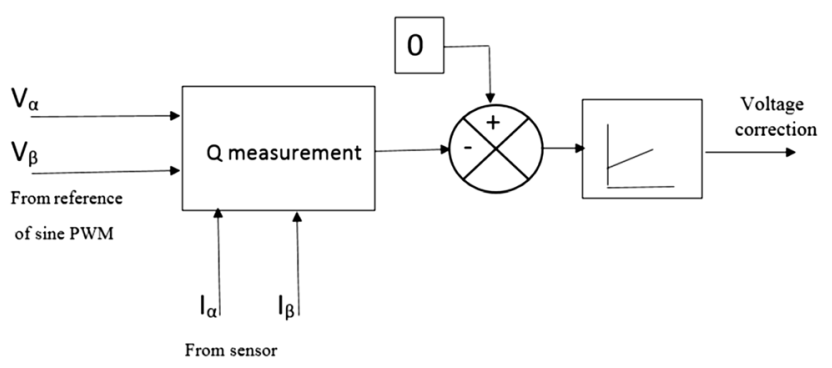

Figure 12. Block diagram of reactive power controller.

It can be seen that the reactive power changes during sudden loading but it becomes zero again at steady state. Figures 14 and 15 show that the steady-state external displacement factor (fundamental power factor) is almost unity. This results in maximum output power per ampere at any particular speed.

Also, figure 14 shows that phase voltage and current are in phase with each other. This verifies that the steady-state 


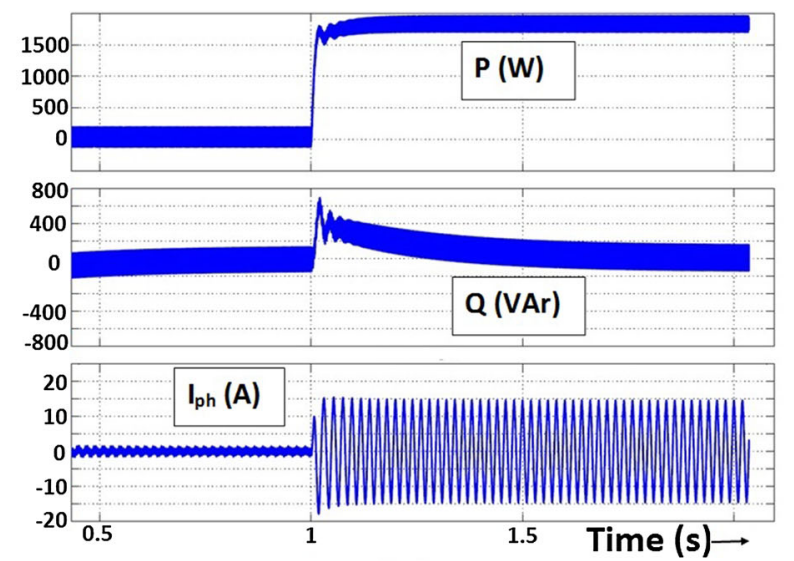

(a)

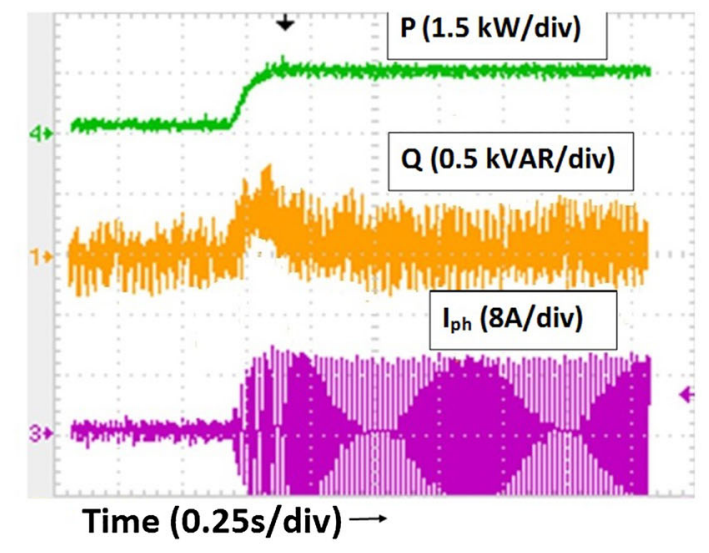

(b)

Figure 13. Active power, reactive power and phase during sudden loading of $25 \mathrm{Nm}$ at $750 \mathrm{rpm}$, (a) simulated result and (b) experimental result.

fundamental power factor is unity and the system achieves zero reactive power operation. Figure 16 provides experimental results showing the dynamic performance at low speed (150 rpm, $0.2 \mathrm{pu}$ speed). It can be verified from figure $16 \mathrm{a}$ that the PMSM operation remains stable under this condition also and speed remains constant even after sudden loading at low speeds also. The reactive power drawn, as claimed earlier, also becomes zero after the transient period. Figure 16b shows steady-state operation at low speed (150 rpm, corresponds to $10 \mathrm{~Hz}$ frequency) with a load of $15 \mathrm{Nm}$. It can be observed that the external displacement factor is almost unity even at this low speed.

The values of $K_{p}\left(0.2\right.$, here) and $K_{i}(1$, here) are chosen (by iteration) in such a way that it does not affect transient response of the machine. This is because the control is being done on stator reference frame without any decoupling between $d$ and $q$-axis. Higher values of $K_{p}$ and $K_{i}$ cause the transient reactive power to get reset to zero faster but result in speed oscillations during starting of the motor (figure 17).

It will be worthwhile to mention that this reactive power controller automatically acts to change the voltage command even when the DC-link voltage falls/rises from the chosen DC-link voltage (during loading or due to input voltage sag, etc.). Thus the reactive power always remains zero and the fundamental power factor remains unity.

The tests results of $V / f$ control-based-PMSM drive (machine ratings are given in the "Appendix") at rated speed with different loads are given in table 4 . It can be seen from results that the efficiency of the drive is very high (close to efficiency values achievable under vector control operation) at rated conditions. The torque-speed and power-speed characteristics for rated current under close-loop $V / f$ control are shown in figure 18. The torque-speed characteristics are very similar to that of a separately excited DC machine (or PMSM under vector control).

It can observed from figure 18 that for constant armature current of $12 \mathrm{~A}$ (rated current) the output power of the machine increases linearly with speed and gives rated output power of $5 \mathrm{~kW}$ at rated speed of $750 \mathrm{rpm}$ (sl. no. 4, table 4) and the output shaft torque remains almost constant at $63 \mathrm{Nm}$ (this is also the rated output torque) up to the rated speed. This proves that the internal power factor remains very close to unity, i.e., back emf (E) and phase current $\left(I_{a}\right)$ are almost in phase for the entire speed range. Figure 18 shows that the torque remains almost constant for the entire speed range and the output power increases linearly with speed.

Now the output torque and power are given by

$$
\begin{array}{r}
T_{e}=\frac{P}{2} \psi_{0} i_{q}-3 i_{a}^{2} r_{a}-\text { core loss }-B \omega, \\
P=\omega\left(\frac{P}{2} \psi_{0} i_{q}-3 i_{a}^{2} r_{a}-\text { core loss }-B \omega\right) .
\end{array}
$$

From (24), constant torque for constant $I_{a}$ (where, $I_{a}=$ $I_{d}+j I_{q}$ (figure 2)) proves that $I_{a} \simeq I_{q}$ and $I_{d} \simeq 0$ at steady state for the entire speed range. Thus, the speed-torque characteristics of the proposed control resemble the steadystate performance of a vector-control-based PMSM drive where $I_{a}=I_{q}$ and $I_{d}=0$. A complete photograph of the test set-up is shown in figure 19 .

\section{Speed reversal and $2 Q$ operation}

The speed reversal and $2 Q$ operation of a 3 -phase IM, running under $V / f$ control, can be done by plugging. However, for the SPMSM the plugging (sudden inter- 


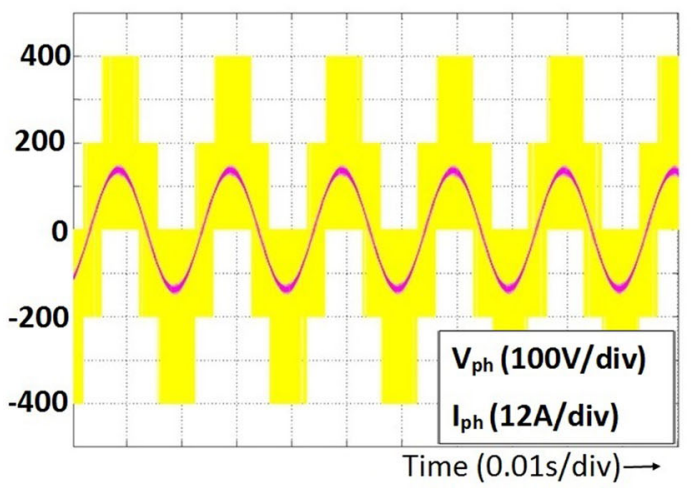

(a)

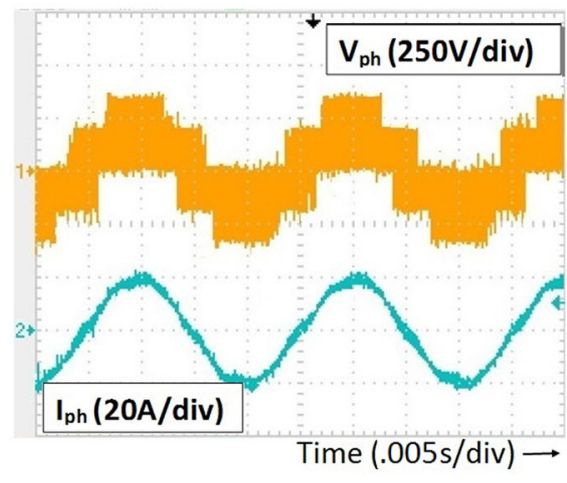

(b)

Figure 14. (a) Simulated Result: $V_{p h}$ (scale: $X$-axis, $10 \mathrm{~ms} /$ div; $Y$-axis, $100 \mathrm{~V} /$ div) and, $\mathrm{I}_{p h}$ (scale: $X$-axis, $10 \mathrm{~ms} / \mathrm{div} ; Y$-axis, $12 \mathrm{~A} /$ div) at steady state and (b) experimental result: $V_{p h}$ (scale: $X$-axis, $5 \mathrm{~ms} / \mathrm{div} ; Y$-axis, $250 \mathrm{~V} /$ div) and $\mathrm{I}_{p h}$ (scale: $X$-axis, $5 \mathrm{~ms} /$ div; $Y$-axis, $20 \mathrm{~A} / \mathrm{div})$ at steady state.

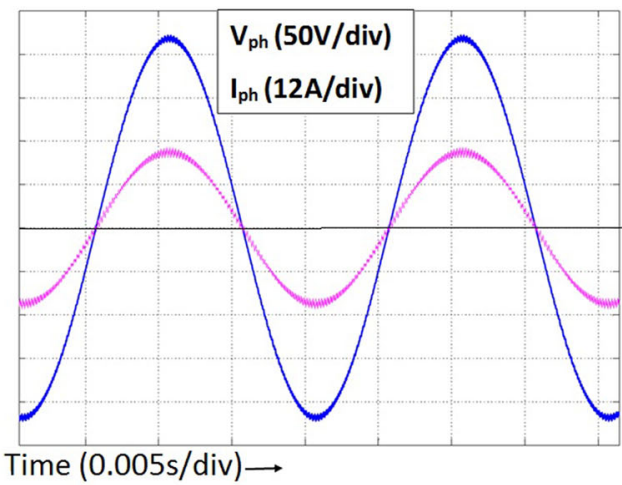

(a)

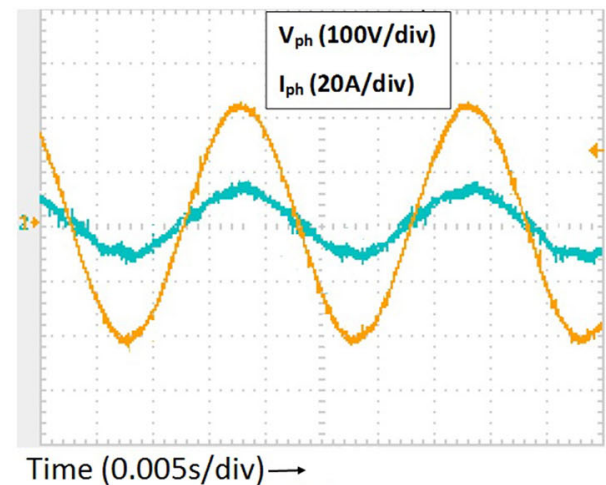

(b)

Figure 15. (a) Simulated result: $V_{p h-r e f}$ and $I_{p h}$ at steady state and (b) experimental result: $V_{p h-r e f}$ and $I_{p h}$ at steady state.

change between 2-phases) will make the machine fall outof-step. Hence a novel speed reversal technique is used here for $V / f$-controlled SPMSM and is shown in figure 20. Here, the rate limiter changes the speed reference slowly to reverse polarity. The polarity of frequency modulation used for stabilisation also has to be reversed for reverse rotation of the motor. Figure 21 shows the change in speed reference and frequency reference during speed reversal. Figure 22 shows the speed reversal of motor from 750 to $-750 \mathrm{rpm}$ with a constant load of $25 \mathrm{Nm}$.

Figure 22 shows that during sudden speed reversal command, actual speed reference decreases slowly, then reverses and finally reaches the reference value. The slope of the frequency rate limiter is decided from motor inertia. Actual speed of the machine follows the reference speed, decreases slowly and finally reverses. It can also be verified that the magnitude of current remains constant. However, the frequency of phase current decreases and again increases as the motor reverses.

\section{Starting of the motor}

Here the $V / f$ drive is started with the conventional $V / f$ control method of boosting the voltage command (represented in the $V-f$ block/curve in figure 1) at low frequency (from crawling speeds up to $5 \mathrm{~Hz}$, here). This is required for starting with load, as at low speeds the drop across stator impedance is not negligible compared with the supply voltage and constant $V / f$ relation at low speed does not ensure constant $\phi$. It is also observed through off-line and real-time simulation that the motor can start from any initial position of the rotor, i.e., initial angular displacement $\theta_{0}$ (i.e., the angle between $d$-axis and R-phase axis at $t=0$ ) 


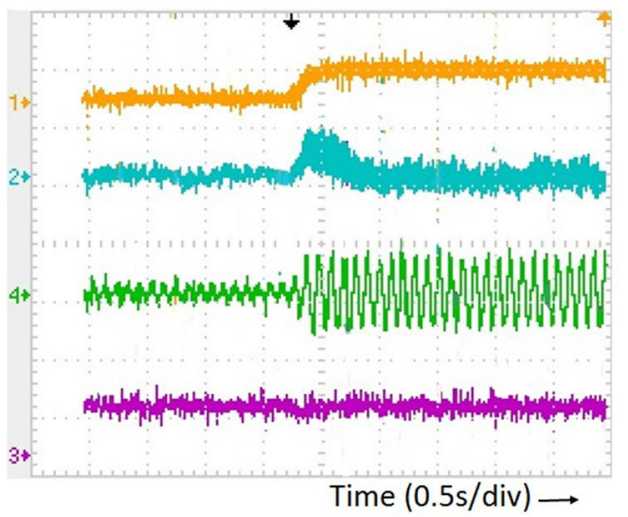

(a)

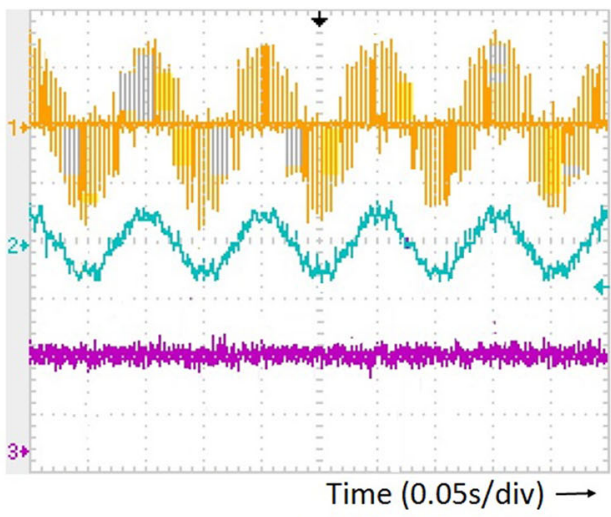

(b)

Figure 16. (a) Channel 1: active power (scale $1 \mathrm{~kW} / \mathrm{div})$, Channel 2: reactive power (500 VA/div), Channel 3: phase current (5 A/div), Channel 4: actual speed (150 rpm/div) during sudden loading of $15 \mathrm{Nm}$; (b) Channel 1: phase voltage (scale 250 V/div Channel 2: phase current (5 A/div), Channel 3: actual speed (75 rpm/div).

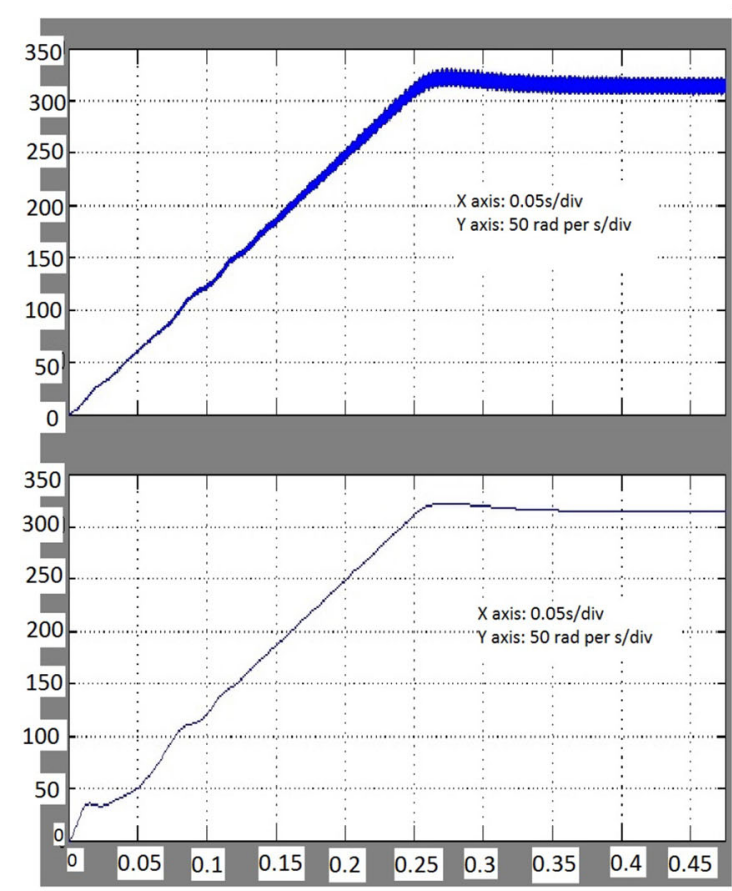

(a)

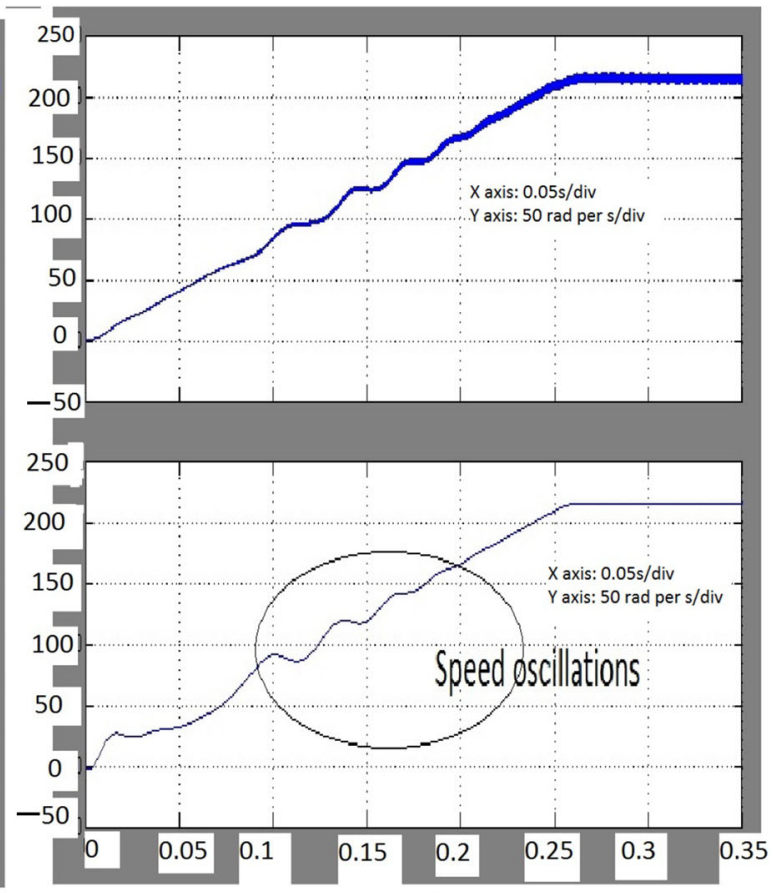

(b)

Figure 17. Voltage command $\left(V^{*}\right)$ (scale: $X$-axis: $50 \mathrm{~ms} /$ div, $Y$-axis: $50 \mathrm{~V} / \mathrm{div}$ ) and $\omega$ (scale: $X$-axis: $50 \mathrm{~ms} / \mathrm{div}, Y$-axis: 50 elec. rad/s) (a) for $K_{p}=0.2, K_{i}=1$ and (b) for, $K_{p}=0.4, K_{i}=2$.

Table 4. Test results of a $5 \mathrm{~kW}$ PMSM under closed-loop $V / f$ control.

\begin{tabular}{lcccccc}
\hline S1. & & & \multicolumn{5}{c}{$\begin{array}{c}\text { Output } \\
\text { power } \\
\text { no. }\end{array}$} & $V_{L L}(V)$ & $I_{p h}(A)$ & $\begin{array}{c}\text { Speed } \\
(\mathrm{rpm})\end{array}$ & $\begin{array}{c}\text { Load } \\
(\%)\end{array}$ & $\begin{array}{c}\text { Efficiency } \\
(\%)\end{array}$ \\
\hline 1 & 264 & 0.6 & 750 & 100 & 2 & 36.8 \\
2 & 268 & 2.1 & 750 & 690 & 14 & 71 \\
3 & 273 & 6.7 & 749 & 2815 & 57 & 89 \\
4 & 278 & 12 & 748 & 5135 & 102 & 92 \\
\hline
\end{tabular}

estimation, which involves complex algorithms and lesser accuracy for SPMSM (i.e., no saliency), is not required for the proposed $V / f$ control system. This is a major practical advantage of this proposed scheme. Figures 23-26 show starting of the PMSM with a load of $10 \mathrm{Nm}$ for various initial positions. It can be seen in the simulated results that the motor starts and rotates smoothly in forward direction for different rotor positions. The same has been experimentally verified also and presented here. This is another highlight of this paper. 


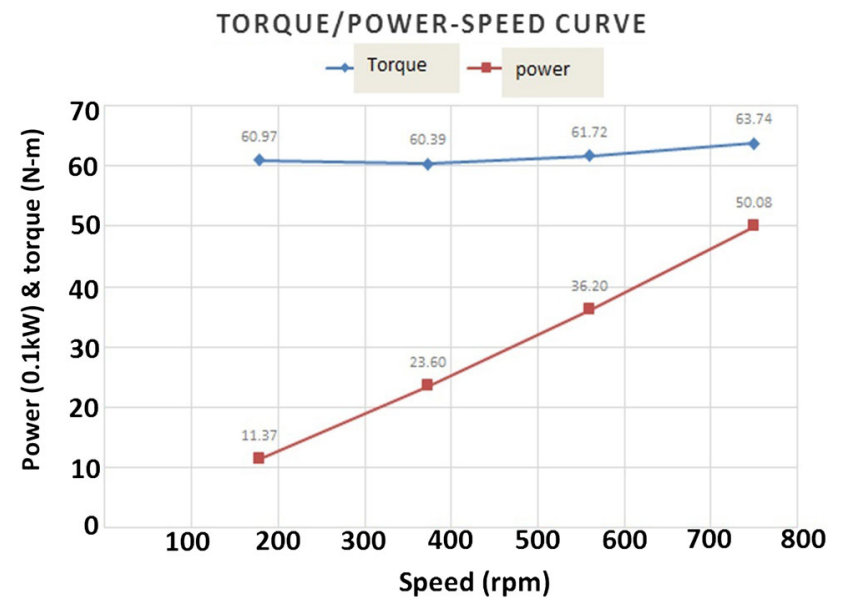

Figure 18. Torque-speed and power-speed characteristics of PMSM under close loop $V / f$ control at a constant current of $12 \mathrm{~A}$.

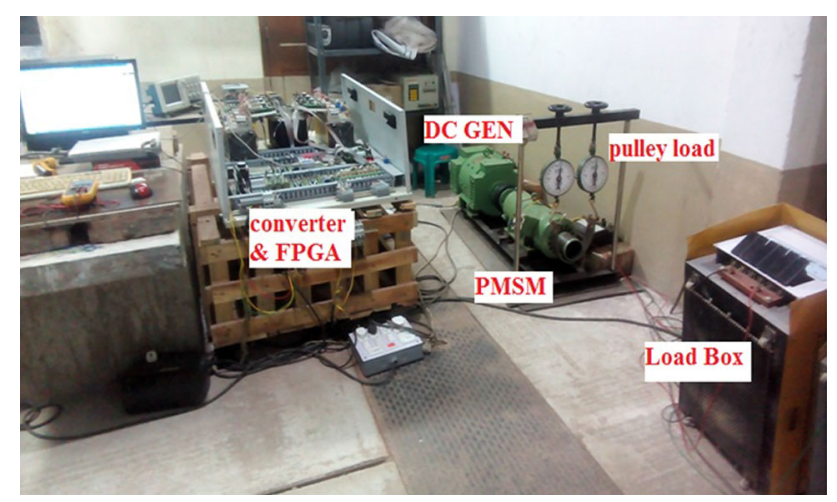

Figure 19. Photograph of the complete test set-up of the PMSM with loading arrangements and the converter.

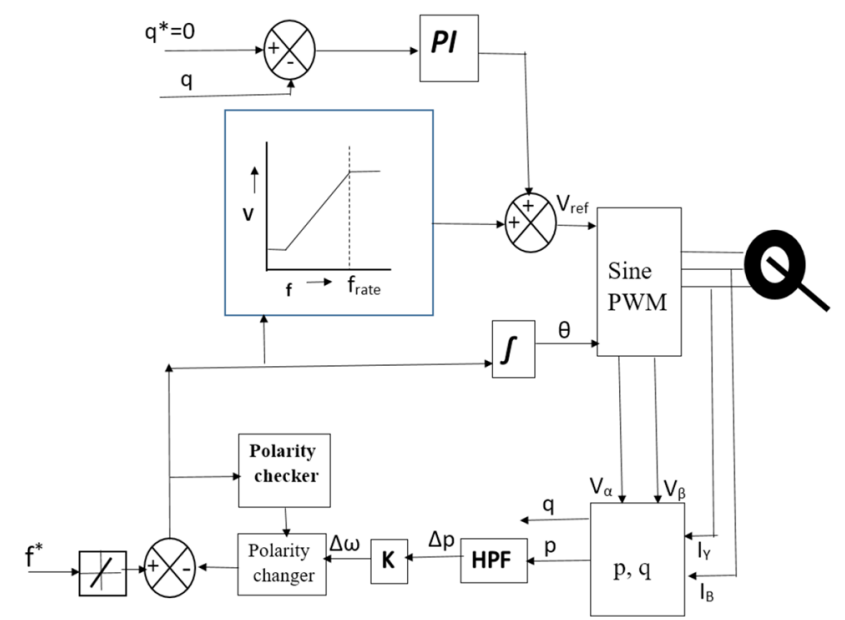

Figure 20. Block diagram of the proposed closed loop $V / f$ control of PMSM with $2 Q$ operation.

Particularly, we can observe in figures $23-26$ that the actual torque angle during starting depends on the initial position of rotor ( $d$-axis) with respect to R-phase axis.
Hence, the torque produced during starting varies for different initial positions. Depending on the initial position the starting torque may be positive or negative. However, as the frequency increases slowly (depends on the slope on rate limiter of frequency command) and hence the rotating magnetic field produced by the stator current slowly develops speed, the rotor gets locked with the rotating magnetic field and starts to rotate in forward direction.

\section{Vector control implementation}

The control technique for vector-control-based PMSM drive is well established [2,3] and has been implemented in this PMSM also. The basic block diagram [16] of conventional vector-control-based PMSM drive is shown in figure 27. It is being briefly discussed here. Vector control involves unit vector generation with rotor angle feedback from the position encoder, forward and reverse reference frame transformations, implementation of PI controller for speed and current control. Continuous feedback of the stator currents and rotor position is therefore required for vector control operation. All these point towards the need for a high-end digital controller (here FPGA). As the unit vectors are generated from machine position and speed, vector control always maintains synchronism even under transient load and speed variation.

The vector control is implemented on rotor reference frame (unlike the $V / f$ control, which is implemented in stator reference frame). The primitive machine model of the PMSM (without any damper winding) may be developed following [15] and is given by

$$
\begin{aligned}
& v_{d}=R i_{d}+L_{d} \frac{d i_{d}}{d t}-w_{e} L_{q} i_{q}, \\
& v_{q}=R i_{q}+L_{q} \frac{d i_{q}}{d t}+w_{e} L_{d} i_{d} .
\end{aligned}
$$

Torque produced by the PMSM can be written as [15] follows:

$$
T_{e}=\frac{P}{2}\left[\psi_{d} i_{q}-\psi_{q} i_{d}\right]
$$

where $\psi_{d}=L_{d} i_{d}+\psi_{0}$ and $\psi_{q}=L_{q} i_{q}$. The mechanical dynamics can be described by

$$
J \frac{d w_{m}}{d t}=T_{e}-T_{L}-B w_{m} .
$$

All the notations carry their usual meanings [15].

Vector control of PMSM involves the following steps:

1. Speed need to be sensed and it should remain constant at the set reference irrespective of load variation. This implies control of developed torque, which means that $i_{q}$ needs to be controlled.

2. $i_{d}$ is usually set to zero. 


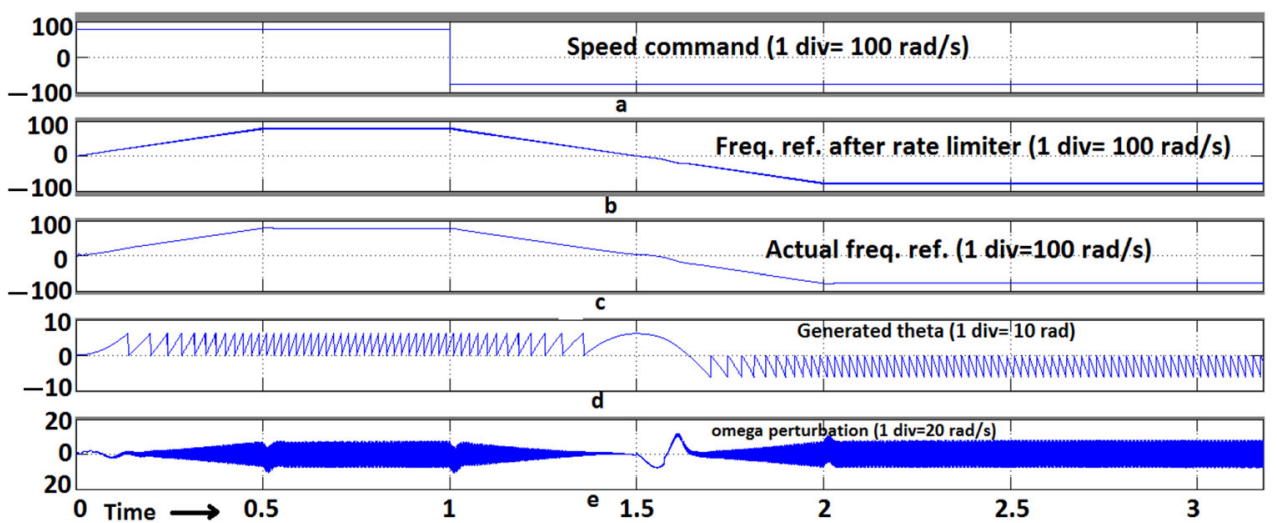

Figure 21. (a) Speed reference, (b) frequency reference after rate limiter, (c) actual speed, (d) theta generated from frequency reference, and (e) omega perturbation during speed reversal of 750 to $-750 \mathrm{rpm}$.

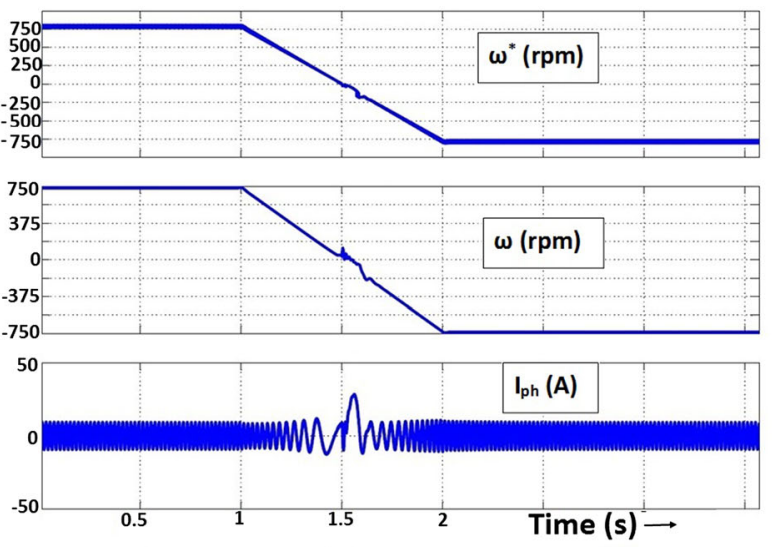

(a)

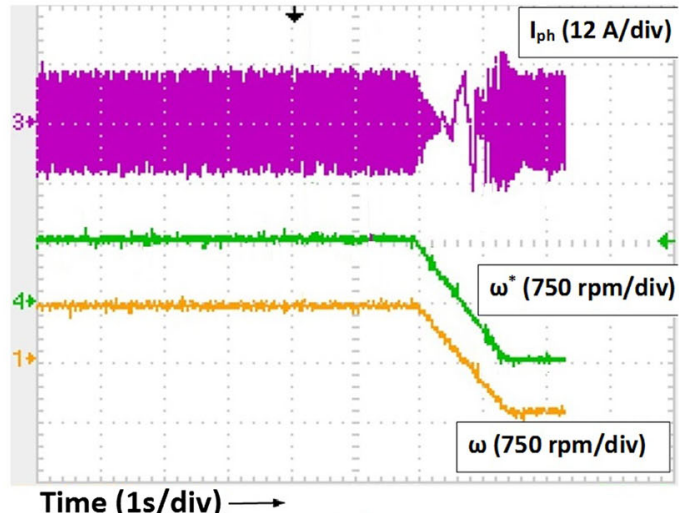

(b)

Figure 22. Speed reference, actual speed and phase current during speed reversal from 750 to -750 rpm: (a) off-line simulation and (b) experimental result.

3. Armature currents need to be sensed.

4. Coupling exists between $d-q$ axis voltages. This needs to be decoupled.

5. Stator voltage in $d-q$ reference frame has to be transformed to stationary reference frame.

6. PWM algorithm has to be executed to generate gating signals.

From (26) and (27), it is seen that the $d$ and $q$-axis voltages are coupled. However, for independent control of $d$ and $q$-axis quantities, it is necessary to decouple the $d$ and $q$-axis voltages.

The same is accomplished following established methods [2]. The development is repeated here for the sake of ready reference. The output of the $d$-axis current controller (figure 28) leads to the relation

$$
v_{s} d^{\prime}=R i_{s d}+L \frac{d i_{s d}}{d t} .
$$

Hence, the response of the $d$-axis current controller is decoupled from the effect of $q$-axis current.

$$
v_{s d}=v_{s d}^{\prime}-w_{e} L i_{s q} .
$$

Similarly, the $q$-axis current controller output leads to the relation

$$
v_{s q}^{\prime}=R i_{s q}+L \frac{d i_{s q}}{d t} .
$$

Hence

$$
v_{s q}=v_{s q}^{\prime}+w_{e} L i_{s q}+w_{e} \psi_{0} .
$$

The detailed control procedure is shown in the block diagram in figure 27.

\section{Comparison of proposed $V / f$ control with vector control}

As mentioned earlier the popular vector control scheme was implemented in this machine to set up a solid basis for establishing the merits and demerits of the novel 


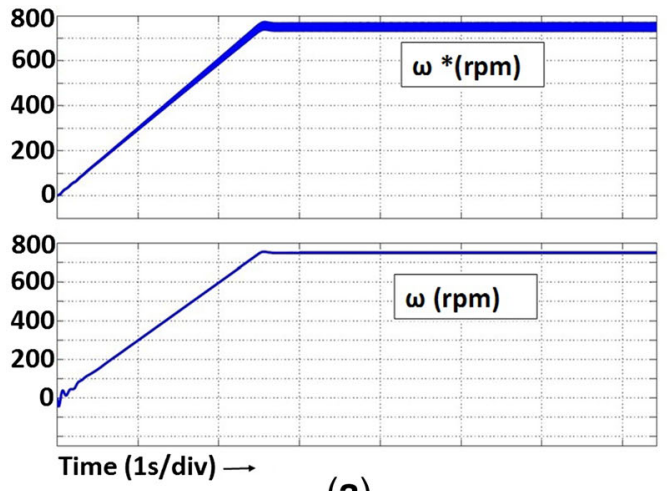

(a)

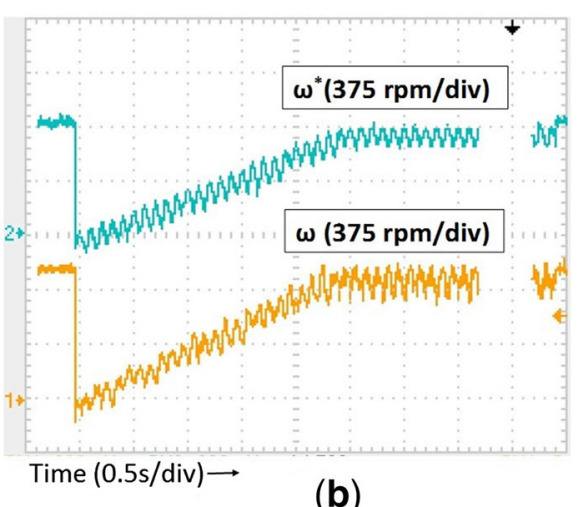

(b)

Figure 23. Starting of motor with $\theta_{0}=0^{0}$ : (a) Off-line simulation and (b) real-time simulation.
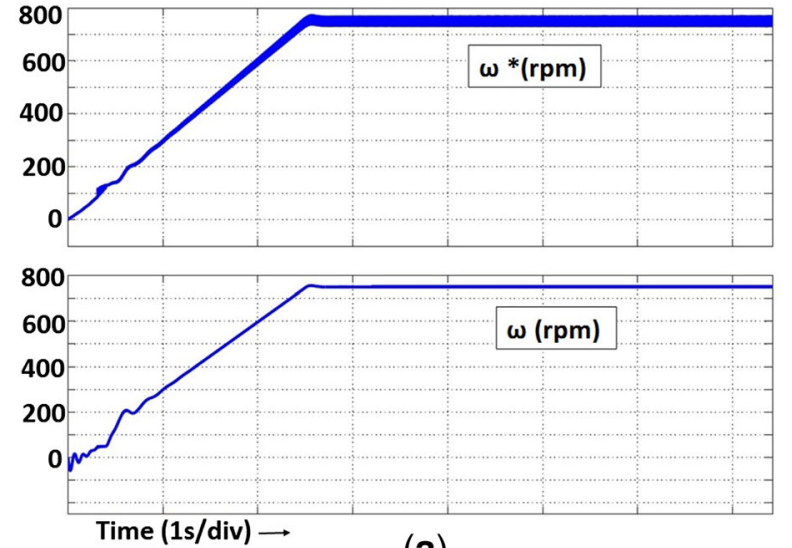

(a)

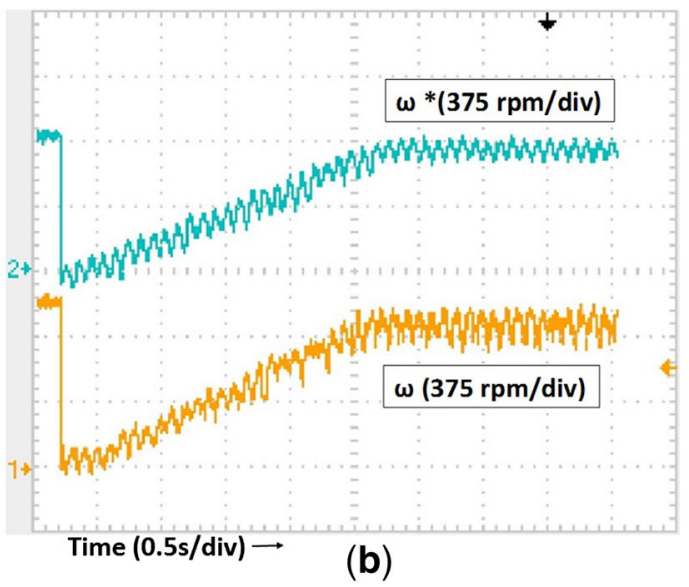

(b)

Figure 24. Starting of motor with $\theta_{0}=90^{\circ}$ : (a) off-line simulation and (b) real-time simulation.

scheme proposed in this paper. This is for the sake of easy technical reference related to this work.

Figure 29a and b shows the starting and loading transients of PMSM under vector control, respectively. It can be seen that speed transient is faster (settling time around $200 \mathrm{~ms}$ ) compared with the $V / f$ control (around 1 s (figure 9)). Independent control on $d$ and $q$-axis current (Unlike $V / f$ control) prevents large speed variations and current oscillation even under sudden loading of machine (figure 29 and 9). The performance of vector control gets affected by parameter variation, such as $L_{d}, L_{q}$, etc. However, the proposed $V / f$ control is independent of any parameter variations. Table 5 lists the relative merits and demerits of the proposed scheme (vis-a-vis the vector control) in a compact manner.

The sensorless vector control [17, 18], which is based on advance control algorithm such as extended Kalman filter (EKF), sliding mode observer, etc., additionally requires knowledge of initial position. This increases the overall complexity and computation required. Also, the estimation of speed and position is not accurate for surface-mounted PMSM $\left(\mathrm{L}_{d}=\mathrm{L}_{d}\right)$ at low speeds. In contrast, the proposed $V / f$ control needs no knowledge of speed position during starting or at any other speed.

It is also found that under closed-loop $V / f$ control operation at any speed (particularly at higher speeds), sudden input power failure/turn-off may cause instability in motor, which causes large phase current and sudden mechanical jerk in the machine (figure 30). The speed should be brought down (at least to $5 \%$ of rated speed) before turning off the drive. However, in case of vector control no such problems occur and the machine comes down to rest smoothly without any jerk (figure 30).

Hence it can be concluded that the proposed $V / f$ control technique is a simple, low-cost, sensorless control technique that can be used for PMSM drive for low to rated speed operation with a very good steady-state performance and efficiency and can be a very good alternative to vector control for many applications (table 6). 


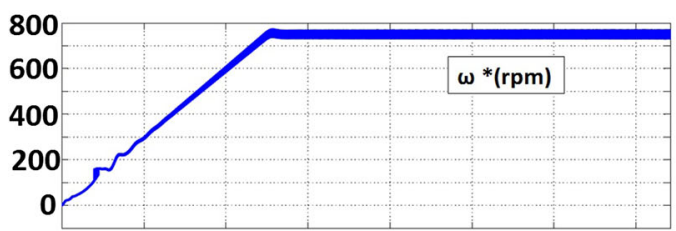

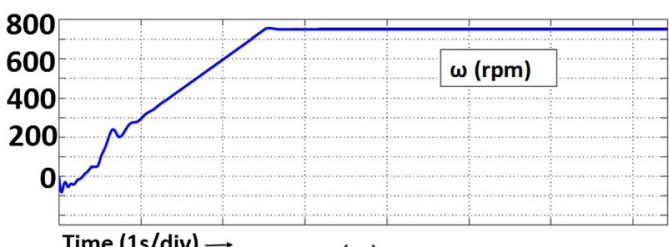

(a)

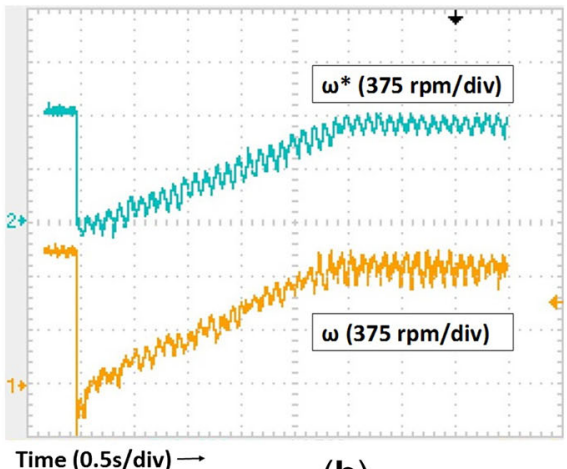

(b)

Figure 25. Starting of motor with $\theta_{0}=180^{\circ}$ : (a) off-line simulation; (b) real-time simulation.
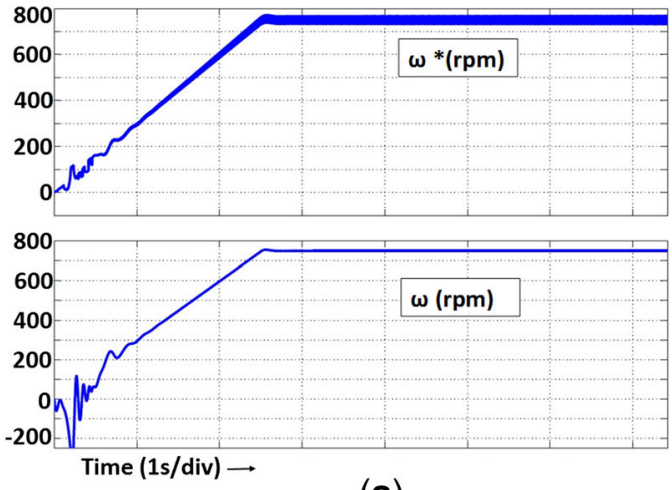

(a)

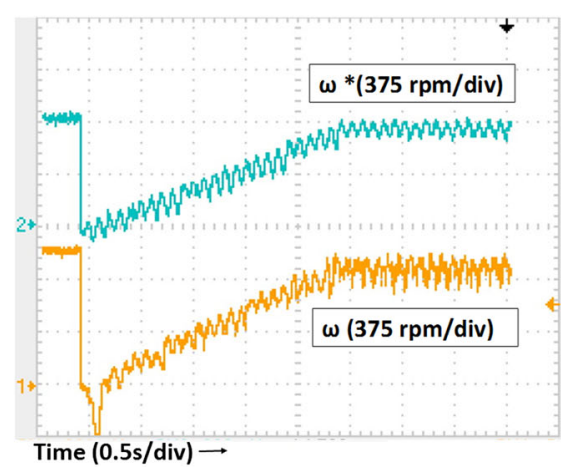

(b)

Figure 26. Starting of motor with $\theta_{0}=-90^{\circ}$ : (a) off-line simulation and (b) real time simulation.

\section{Conclusions}

Here, a novel closed-loop stable $V / f$ control of a 8-pole, $750 \mathrm{rpm}, 5 \mathrm{~kW}$, surface-mounted PMSM (design and fabricated by the same authors) has been proposed and practically implemented. The inherent instability of open-loop $V / f$ drive has been eliminated with proper frequency modulation with the help of power perturbation. The proposed scheme eliminates the need for any shaft-mounted speed or position sensor. This $V / f$ control method is found to be unaffected by parameter variations. The efficiency of the motor has been maximised by making the reactive power to zero. Simulated results along with basic analysis of the system proves the instability of open-loop V/f control above $500 \mathrm{rpm}$. However, the PMSM runs smoothly without any instability or sustained oscillation with the closed-loop frequency modulation. A comparative study of the proposed
V/f control method with vector control method has also been presented in this paper. This establishes the simplicity, easy implementation, higher efficiency and robustness of the proposed $V / f$ drive. It is emphasised that $V / f$ control does not involve any forward or reverse axis transformation unlike vector control. This reduces the complexity and computation required. Moreover, sensorless vector control requires the knowledge of initial position of rotor. However, initial position estimation for surface-mounted PMSM $\left(L_{d}=L_{q}\right)$ itself is a research area and involves complex algorithms. Moreover, the estimated speed and rotor position at lower speed range suffer accuracy problems which affect the performance of sensorless vector control.

However, in the proposed scheme presented in this paper, knowledge/feedback of initial position or speed signal is not required. It may be worthwhile to point out that the proposed $V / f$ control is also independent of 

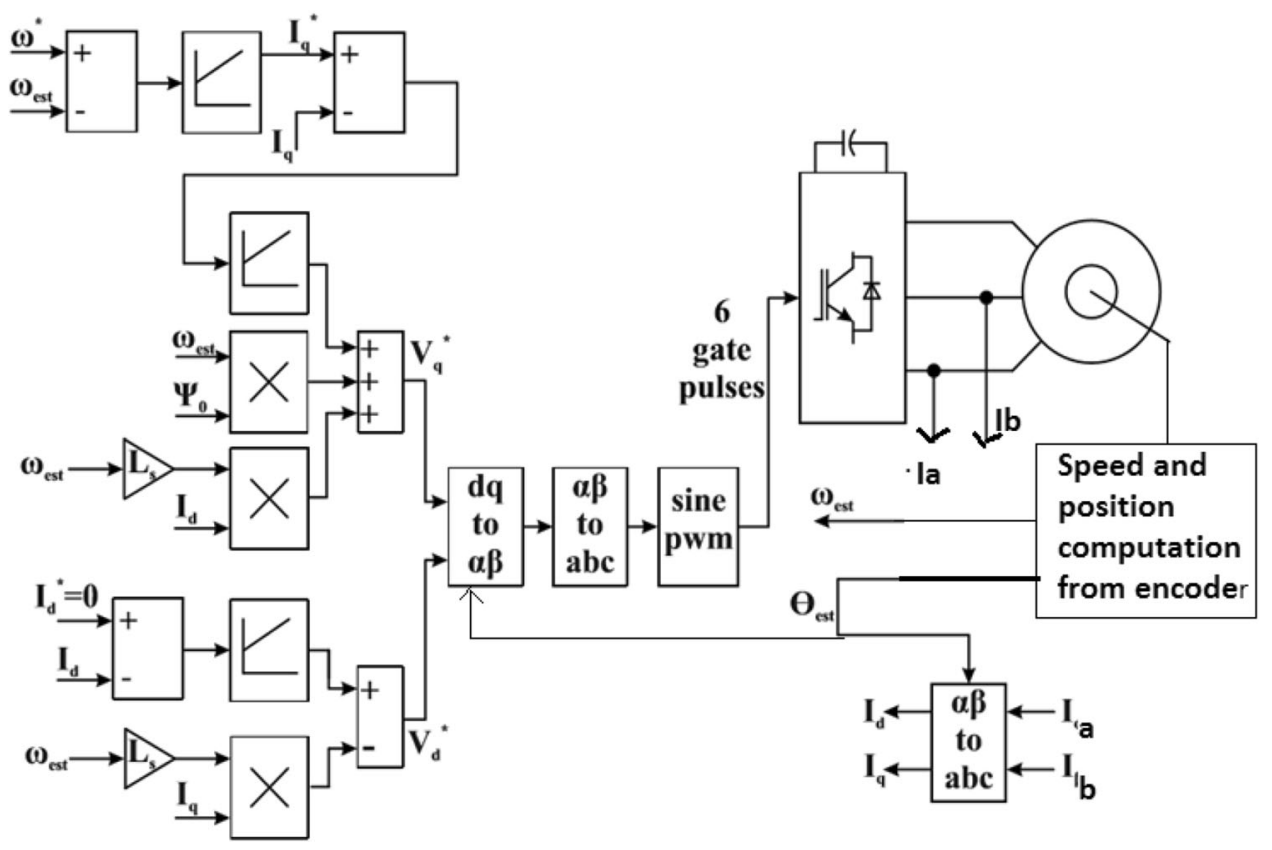

Figure 27. Block diagram of vector-control-based PMSM drive.
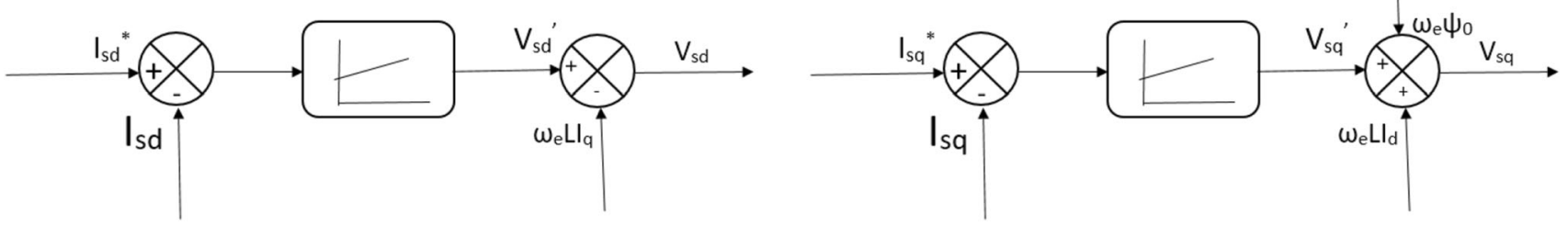

Figure 28. (a) $d$-axis current control loop and (b) $q$-axis current control loop.

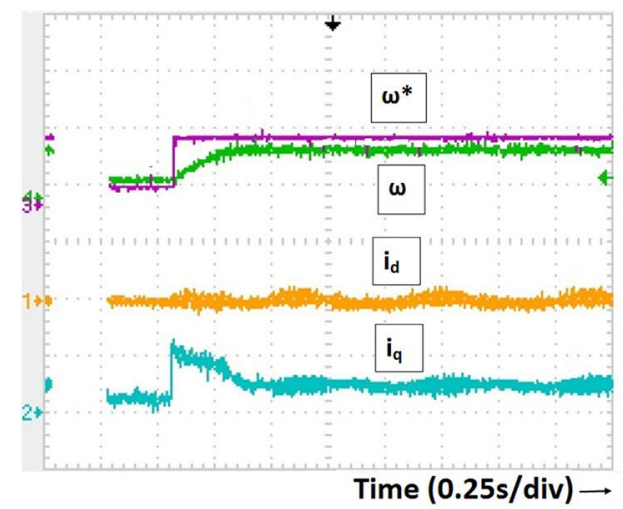

(a)

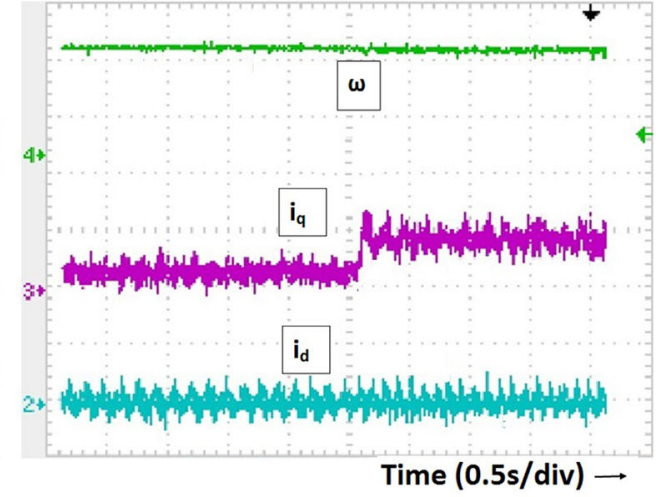

(b)

Figure 29. Vector control operation: (a) PMSM ramping up from 0 to $750 \mathrm{rpm}, i_{d}, i_{q}$; (b) actual speed, $i_{q}, i_{d}$ during sudden loading of $0.8 \mathrm{~kW}$ at $750 \mathrm{rpm}$. 
Table 5. Comparison on closed loop $V / f$ control and vector control.

\begin{tabular}{|c|c|c|}
\hline Item/parameter & Close-loop $V / f$ control & Vector control \\
\hline $\begin{array}{l}\text { Speed } \\
\text { response }\end{array}$ & $\begin{array}{c}\text { Limited by motor } \\
\text { inertia }\end{array}$ & $\begin{array}{l}\text { Depends on the } \\
\text { controller design }\end{array}$ \\
\hline $\begin{array}{l}\text { Complexity } \\
\text { and } \\
\text { computation }\end{array}$ & Much lower & $\begin{array}{c}\text { Higher (requires high- } \\
\text { end processors) }\end{array}$ \\
\hline $\begin{array}{l}\text { Parameter } \\
\text { dependence }\end{array}$ & No & Yes \\
\hline Operating p.f. & External u.p.f. & Internal u.p.f. \\
\hline $\begin{array}{l}\text { Starting torque } \\
\text { (for the } \\
\text { same } \\
\text { current) }\end{array}$ & Lower & Higher \\
\hline $\begin{array}{r}\text { Zero-speed } \\
\text { operation }\end{array}$ & Not possible & Possible \\
\hline $\begin{array}{c}\text { Sensorless } \\
\text { scheme }\end{array}$ & Inherently sensorless & $\begin{array}{l}\text { Requires sensor and/or } \\
\text { complex algo-rithm } \\
\text { for position and } \\
\text { speed estimation }\end{array}$ \\
\hline Applications & $\begin{array}{l}\text { Low-cost and low- } \\
\text { performance drives, } \\
\text { e.g., high-speed } \\
\text { fans, pumps, etc. }\end{array}$ & $\begin{array}{l}\text { High-performance } \\
\text { drive like traction, } \\
\text { cranes, lift, etc. }\end{array}$ \\
\hline
\end{tabular}

parameter variations. On the other hand, the performance of any sensorless vector control scheme gets affected by the parameter variations with loading or temperature variation.
Table 6. Ratings and other parameters of the PMSM.

\begin{tabular}{lc}
\hline Parameter & Value \\
\hline$L_{d}=L_{q}$ & $5.5 \mathrm{mH}$ \\
$R$ & $0.7 \Omega$ \\
$\psi_{0}$ & $0.76 \mathrm{~V} \mathrm{~s}$ \\
No. of poles $p$ & 8 \\
Rated speed & $750 \mathrm{rpm}$ \\
$J$ & $0.019 \mathrm{~kg} \mathrm{~m}{ }^{2}$ \\
$B$ & $0.04 \mathrm{Nm} \mathrm{s} / \mathrm{rad}$ \\
$I_{\text {rated }}$ & $12 \mathrm{~A}$ \\
$E_{\text {ph }}$ & $145 \mathrm{~V}$ \\
\hline
\end{tabular}

The different control techniques such as EKF, sliding mode controller, etc. that are used in sensorless vector control involve more complex algorithms with increased computation effort. In contrast, the proposed $V / f$ control is very simple, as claimed earlier, and possesses some important advantages over the sensorless vector control with very similar steady-state performance. This has been now highlighted in different parts of the text of the paper (sections 1, 7, etc.)

The simulated and experimental results of the closedloop $V / f$ control have been presented here. Simulated and experimental results are in excellent correlation with each other and in perfect agreement with theoretical analysis. This drive is perhaps more suited to applications where efficiency and simplicity are more important than high dynamic performance, notably in pump, fan, compressor drives, etc.

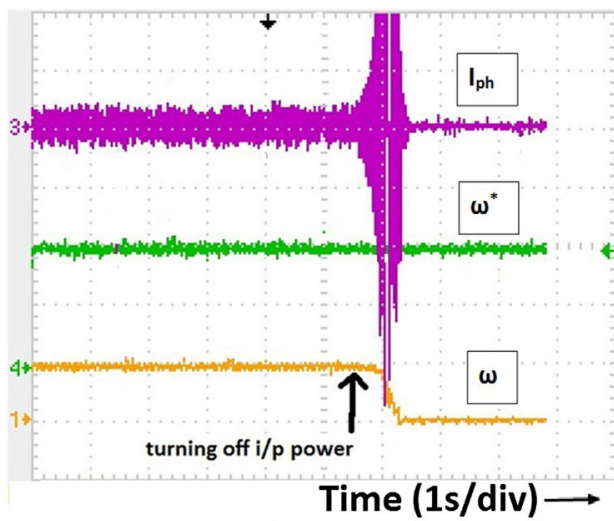

(a)

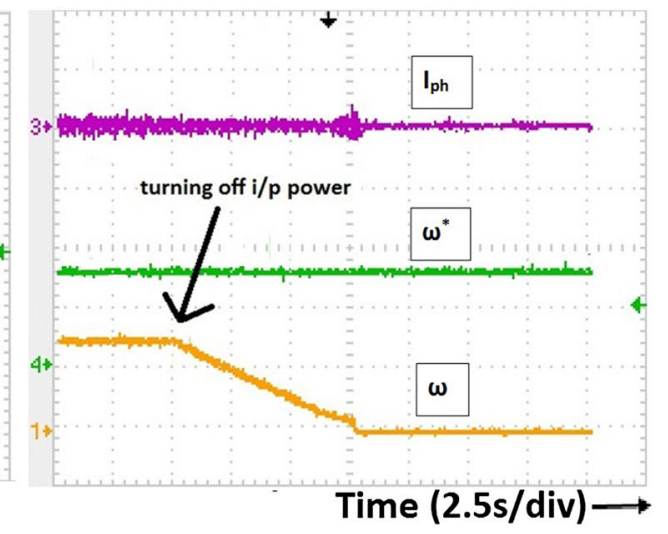

(b)

Figure 30. Phase current, speed reference and actual speed during sudden input power turn-off (a) under $V / f$ control and (b) under vector control. 


\section{Acknowledgements}

The authors would like to express their gratitude for the generous fund support received from the NaMPET-II initiative of the DeitY, MCIT, Government of India. The authors wish to thank GE Motors, Sheoraphully, specially Mr Kausik Pyne, for the support in prototype fabrication. The authors also thank Veeral Controls, Gandhinagar, for fabrication of the converter and the assistance received from the IIEST authorities and research colleagues at the Advanced Power Electronics Laboratory, Department of EE, IIEST, particularly Mr N Dutta.

\section{Appendix}

See table 6 .

\section{References}

[1] Zhong L, Rahman M F, Hu W Y and Lim K W 1997 Analysis of direct torque control in permanent magnet synchronous motor drives. IEEE Trans. Power Electron. 12(3): $528-536$

[2] Bae B H, Sul S K, Kwon J H and Byeon J S 2003 Implementation of sensorless vector control for super-high-speed PMSM of turbo-compressor. IEEE Trans. Ind. Appl. 39(3): 811-818

[3] Seok J K, Lee J K and Lee D C 2006 Speed-sensorless vector control for permanent-magnet synchronous motors based on instantaneous reactive power in the wide-speed region. IEEE Trans. Ind. Electron. 53(2): 399-405

[4] Fallside F and Wortley A T 1969 Steady-state oscillation and stabilisation of variable-frequency invertor fed induction motor drives. Proc. IEEE 116(6): 991-999

[5] Koga K, Ueda R and Sonoda T 1990 Constitution of V/f control for reducing the steady state speed error to zero in induction motor drive system. In: Proceeding of the IEE IAS Annual meeting, vol. 1, pp. 639-646

[6] Cornell E P and Novotny D W 1972 Theoretical and experimental analysis of operating point stability of synchronous machines. IEEE Trans. Power Apparatus Syst. PAS-91(1): 241-248
[7] Verghese G C, Lang J H and Casey L F 1986 Analysis of instability in electric machines. IEEE Trans. Ind. Appl. IA22: 853-864

[8] Lipo T A and Krause P C 1967 Stability analysis for variable frequency operation of synchronous machines. IEEE Trans. Power Appl. Syst. 3: 227-234

[9] Colby Roy S and Novotny Donald W 1988 An efficiencyoptimizing permanent-magnet synchronous motor drive. IEEE Trans. Ind. Appl. 24: 104-112

[10] Kiuchi M, Ohnishi T, Hagiwara H and Yasuda Y 2010 V/f control of permanent magnet synchronous motors suitable for home appliances by DC-link peak current control method. In: Proceedings of the International Power Electronics Conference, pp. 567-573

[11] Bose B K 1997 Power electronics and variable frequency drives. Technology and applications. New York: IEEE Press

[12] Chandana Perera P D, Blaabjerg F, Pedersen J K and Thogersen P 2003 A sensorless, stable V/f control method for permanent-magnet synchronous motor drives. IEEE Trans. Ind. Appl. 39: 783-791

[13] Paitandi S and Sengupta M 2014 Design, fabrication and parameter evaluation of a surface mounted permanent magnet synchronous motor. In: Proceeding of the IEEE International Conference on Power Electronics, Drives and Energy Systems (PEDES)

[14] Paitandi S and Sengupta M 2013 Design, analysis of a surface mounted permanent magnet synchronous motor and its comparison with an Induction motor of same nominal rating. In: Proceedings of the National Power Electronics conference (NPEC)

[15] O'Kelly D and Simmons S 1968 Generalized electrical machine theory. London: Mcgraw Hill

[16] Ranganathan V T 2006 Lecture notes on electrical drives. Bangalore, India: IISc

[17] Quan L, Wang Z and Liu X 2014 Sensorless control of SPMSM using complex number model based position estimation and EKF. In: Proceedings of the 26th Chinese Control and Decision Conference (2014 CCDC), pp. 2663-2668

[18] Yaojing F, Kai Y and Thogersen P 2010 Research of sensorless control for permanent magnet synchronous motor systems. In: Proceedings of the International Conference on Electrical Machines and Systems (ICEMS), pp. 1282-1286 